\title{
PCA and VTEC climatology at midnight over mid-latitude regions
}

\author{
M. P. Natali ${ }^{1,2^{*}}$ and A. Meza ${ }^{1,2}$
}

\begin{abstract}
The effect of the thermospheric vertical neutral wind on vertical total electron content (VTEC) variations including longitudinal anomaly, remaining winter anomaly, mid-latitude summer night anomaly, and semiannual anomaly is studied at mid-latitude regions around zero magnetic declination at midnight during high solar activity. By using the principal component analysis (PCA) numerical technique, this work studies the spatial and temporal variations of the ionosphere at midnight over mid-latitude regions during 2000-2002. PCA is applied to a time series of global vTEC maps produced by the International Global Navigation Satellite System (GNSS) Service. Four regions were studied in particular, each located at mid-latitude and approximately centered at zero magnetic declination, with two in the northern hemisphere and two in southern hemisphere, and all are located near and far from geomagnetic poles in each case. This technique provides an effective method to analyze the main ionospheric variabilities at mid-latitudes. PCA is also applied to the VTEC computed using the International Reference lonosphere (IRI) 2012 model, to analyze the capability of this model to represent ionospheric variabilities at mid-latitude. Also, the Horizontal Wind Model 2007 (HWM07) is used to improve our climatology interpretation, by analyzing the relationship between vTEC and thermospheric wind, both quantitatively and qualitatively. At midnight, the behavior of mean vTEC values strongly responds to vertical wind variation, experiencing a decrease of about $10-15 \%$ with the action of the positive vertical component of the field-aligned neutral wind lasting for $2 \mathrm{~h}$ in all regions except for Oceania. Notable results include: a significant increase toward higher latitudes during summer in the South America and Asia regions, associated with the mid-latitude summer night anomaly, and an increase toward higher latitudes in winter in the North America and Oceania regions, highlighting the remnant effect of the winter anomaly. Finally, the longitudinal variations of eastwest differences, named longitudinal anomaly, show maximum values in March for North America, in December for South America and Oceania, and are not shown for Asia. Our results show that at mid-latitudes regions, the IRI model represents midnight ionospheric mean values with a similar spatial distribution, but the values are always lower than those obtained by GNSS. The differences between IRI and GNSS results include: the longitudinal anomaly is characterized by a stronger semiannual variation in both North America and South America, with a maximum in the equinoxes, while for the Asian region, the behavior is almost constant throughout the years, and finally, there is an absence of the winter anomaly remnant.
\end{abstract}

Keywords: Mid-latitude ionosphere, Neutral wind, Longitude difference of vTEC

\footnotetext{
*Correspondence: paula@fcaglp.unlp.edu.ar

${ }^{1}$ Laboratorio de Meteorología espacial, Atmósfera terrestre, Geodesia, Geodinámica, diseño de Instrumental y Astrometría (MAGGIA), Facultad de Ciencias Astronómicas y Geofísicas (FCAG), Universidad Nacional de La Plata (UNLP), Paseo del Bosque s/n (1900), B1900FWA La Plata, Argentina Full list of author information is available at the end of the article
} 


\section{Introduction}

At mid-latitude, the electron content in the ionosphere is primarily caused by solar irradiance. This effect varies on different timescales, but the rate of change of electron density also depends on loss processes, by recombination, and by electron movement (in terms of mean drift velocity), all of which are related by the continuity equation. According to the Chapman photochemical theory (Rishbeth and Garriot 1969), ionospheric electron content should have a diurnal variation with maximum values at noontime, when the solar zenith angle is lowest. Ionospheric electron density at any time and location depends on many factors: the composition of the neutral atmosphere and its physical conditions, such as density and temperature, the solar spectrum and any energetic particle fluxes able to ionize the atmospheric plasma, and finally the loss processes, both chemical and by transport. The production mechanism and the recombination process mainly depend on the concentrations of atomic oxygen and molecular nitrogen, respectively.

At night, solar irradiance almost disappears (sometimes existing due to a later sunset in summer); therefore, the main factors controlling electron concentration are the initial conditions of ionospheric plasma (i.e., before starting the night) and the loss processes. In the latter, the vertical wind modifies the recombination conditions, when the atmospheric plasma is moved. The vertical movement of ionization is caused by the field-aligned meridional winds component (it is in terms of equatorward and eastward wind components) and the eastward electric field (Rishbeth 1998). Some authors also propose the downward plasmaspheric flux as an additional cause of the electron content increase during night hours (Mikhailov et al. 2000; Richards et al. 2000).

Studies on vTEC behavior have an important role in our understanding of ionosphere-thermosphere coupling. The spatial and temporal variations of vTEC describe the coupling processes of neutral gas in the thermosphere and the plasma in the ionosphere.

At night and at mid-latitudes, the ionosphere is characterized by: annual and semiannual temporal variations (Rishbeth 1998), the mid-latitude summer night anomaly (MSNA) (Liu et al. 2010; Lin et al. 2010), and the eastwest difference (Xu et al. 2013; Zhao et al. 2013). The MSNA has its origin in the Weddell Sea Anomaly, which is characterized by higher electron densities during the night than during the day near the Antarctic Peninsula. Some authors point out that the major reasons for producing this anomaly may be the increase in electron density at the southern part of the Equatorial Ionospheric Anomaly (EIA) along with stronger neutral winds to the equator at longitude $90^{\circ} \mathrm{W}$ ( $\mathrm{Lin}$ et al. 2009). The offset of the magnetic equator to the south and the magnetic declination to the east also contributes to this anomaly. A similar anomalous feature was found in the northern hemisphere $\left(40^{\circ} \mathrm{N}-60^{\circ} \mathrm{N}\right.$ latitude and $120^{\circ} \mathrm{E}-140^{\circ} \mathrm{E}$ longitude) in the June solstice. Thampi et al. (2009) highlight two features of the MSNA: (1) the electron density is higher during night than daytime, and (2) often at night, the electron density at mid-latitudes remains higher than at lower latitudes.

Lastly, some authors report an ionospheric east-west difference in both sides of the longitudes with zero magnetic declination (Zhang et al. 2011; Xu et al. 2013; Zhao et al. 2013), hereafter named longitudinal anomaly. They suggested that this longitudinal anomaly is caused by the difference in magnetic declination that gives rise to upward and downward ion drifts across the zero declination for a given thermospheric zonal wind direction.

In our study, we attempt to link the vTEC data, obtained from Global Navigation Satellite System (GNSS) observations (Mannucci et al. 1998), to the vertical component of the field-aligned neutral wind $(V)$ obtained by the Horizontal Wind Model 2007 (HWM07) (Drob et al. 2008) to describe the behavior of the ionosphere. To do so, we summarize results from previous studies and provide a more complete climatology for different regions at mid-latitude that are approximately centered at zero magnetic declination. Besides vTEC data, this climatology description is completed using the International Reference Ionospheric model 2012 (IRI 2012), highlighting similarities and limitations of the model.

Our result in the manuscript is not simply a comparison corresponding to mid-latitude region results, as it raises new features that are worth further study and that improve our current understanding of ionospheric variabilities.

The numerical technique PCA is applied to the three kinds of data sets. The main PCA modes define the most important variabilities, allowing us to link them to physical processes. "Data and methodology" section describes the data and models used and outlines the numerical technique applied to the data sets. "Results" section presents results for global vTEC maps, for the IRI 2012 model and for HMW07. "Discussion and conclusions" section presents a discussion and conclusions.

\section{Data and methodology}

Four regions in the northern and southern hemisphere (Fig. 1), approximately centered at zero magnetic declination, were selected to study the climatology at mid-latitude regions. In each region, two sectors were highlighted: one in the east (red rectangle) and the other in the west (blue rectangle), with respect to longitudes with zero declination. In this section, the data, models, and numerical tool are described. 


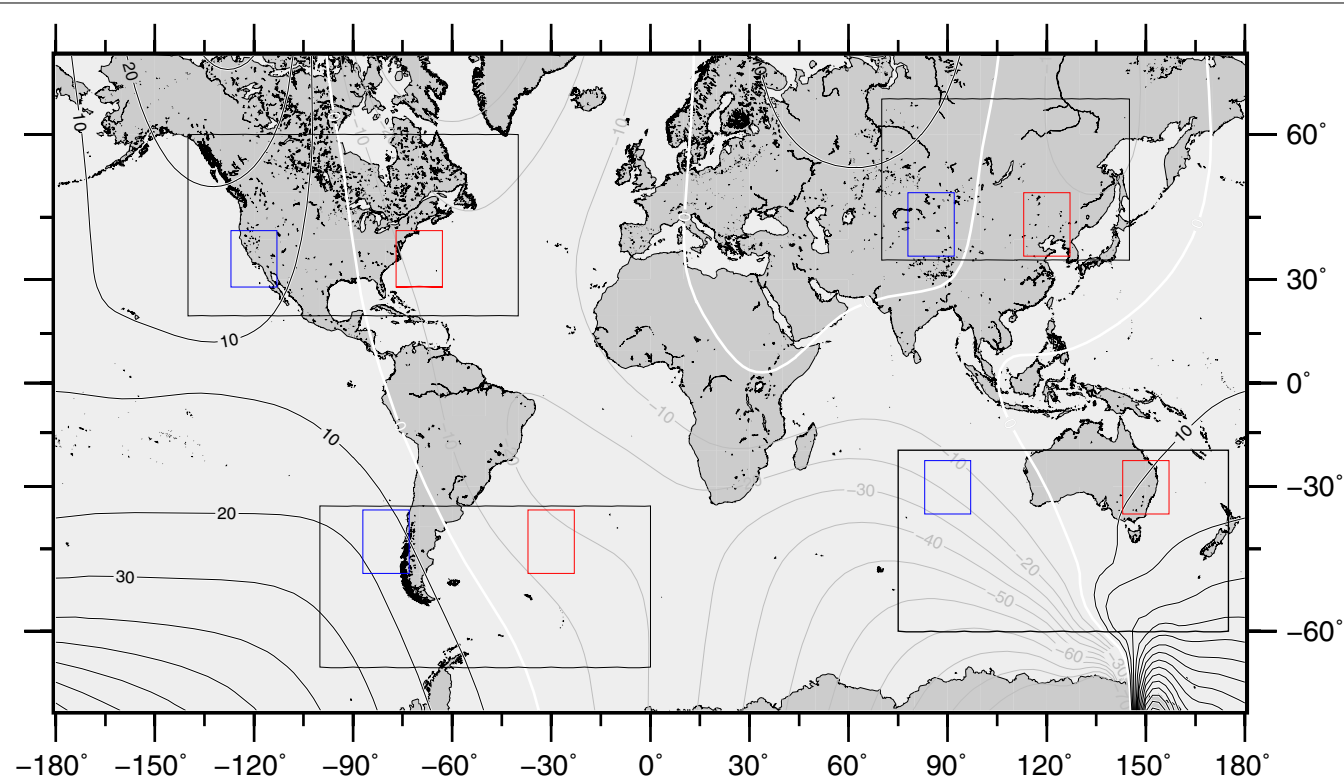

Fig. 1 Regions in the northern and southern hemisphere approximately centered at zero magnetic declination. The zero magnetic declination is along the white line

\section{vTEC from GNSS}

Global vTEC maps from the International GNSS Service (IGS) were used in this work. These maps provide ionospheric electron content information every $2 \mathrm{~h}$ in a grid comprising latitude and longitude of $2.5^{\circ}$ and $5^{\circ}$, respectively (Mannucci et al. 1998).

Three years of high solar activity, spanning 2000-2002, were selected. The data set was ordered to obtain one map per day at local midnight. To do this, slices of $30^{\circ}$, each centered on the same local time, were considered. This selection was based on the assumption that the ionosphere does not change in a 2-h window. Then, the slices were merged into a new vTEC map corresponding to their central longitude. Thus, following this procedure, a new vTEC map, hereafter called $\mathrm{vTEC}_{\mathrm{GNSS}}$, was built to match the local time selected.

\section{VTEC from the IRI 2012 model}

Simulated data were generated using the IRI 2012 model (Bilitza et al. 2014). It is a highly recommended empirical model of the ionosphere, built up by an international working group since the 1960s. Several steadily improved editions of the model have been released. For a given location, time, and date, IRI describes the electron density, electron temperature, ion temperature, and ion composition at an altitude range of approximately $50-2000 \mathrm{~km}$ and also the electron content. It provides monthly averages in the non-auroral ionosphere for magnetically quiet conditions.
The IRI model was used to generate vTEC data, hereafter called $\mathrm{vTEC}_{\mathrm{IRI}}$, at the same grid coordinates as vTEC $_{\text {GNSS }}$ and the same local times.

\section{$V$ from the HWM07 model}

Meridional winds cause ionization to move up or down the magnetic field lines, to regions of slower or faster loss (Titheridge 1995). The meridional wind is:

$$
W_{\mathrm{m}}=W_{\text {equ }} \cos \delta \pm W_{\text {east }} \sin \delta
$$

where $W_{\text {equ }}$ and $W_{\text {east }}$ are the equatorward and eastward components, respectively, $\delta$ is the magnetic declination, and the + and - signs apply in the southern and northern hemisphere. The horizontal wind $W_{\mathrm{m}}$ has a fieldaligned component $W_{\|}=W_{\mathrm{m}} \cos I$ and a perpendicular component $W_{\perp}=W_{\mathrm{m}} \sin I$, where $I$ is the dip angle. $W_{\perp}$ has no effect on the ionization, while $W_{\|}$carries the ionization along the field line, giving an effective vertical velocity, $W_{\|} \sin I$. Thus, an effective vertical component of the field-aligned neutral wind $(V)$, which can move only in a direction parallel to the magnetic field, is:

$$
V=W_{\mathrm{m}} \cos I \sin I
$$

where $V$ describes the overall effect of the wind, for different values of declination and dip magnetic angle, in lifting or lowering the $\mathrm{F} 2$ region.

It is known that wind models often differ $20 \%$ or more (David et al. 2014). The Horizontal Wind Model (HWM07) (Drob et al. 2008) is chosen to compute 
the thermospheric wind values at $300 \mathrm{~km}$, taking into account that this model gives an acceptable mean behavior of $V$ to explain the vTEC variability studied in this work.

HWM07 provides a statistical representation of the horizontal wind fields of the Earth's atmosphere from the ground to the exosphere $(0-500 \mathrm{~km})$. It represents over 50 years of satellite, rocket, and ground-based wind measurements. The computer model is a function of geographic location, altitude, day of the year, solar local time, and geomagnetic activity.

Finally, HWM07 was used to generate $V$ at the same regions as vTEC data, hereafter called $V_{\text {HWM07. In this }}$ case, only 2001 data were used because the HMW07 does not change with solar cycle (Hagan 1993; Burns et al. 2014).

\section{Numerical tool}

PCA is widely used in different areas of science. One of the most interesting advantages of this technique is the decomposition of a correlated data set on a new orthonormal base of minimum dimension.

In this work, we used this technique to describe the climatology at different mid-latitude regions. The data as described in "vTEC from GNSS," "vTEC from the IRI 2012 model," and " $V$ from the HWM07 model" sections were the vTEC $_{\text {GNSS, }}$ vTEC IRI , and $V_{\text {HWM07 }}$. We present a brief description of the technique in "Appendix," and further details about the algebraic foundations of PCA can be found in Preisendorfer (1988) and Wackernagel (1998).

\section{Results}

Figure 2 shows the average values of vTEC $_{\text {GNSs }}$ and $V_{\text {HWM07 }}$ for each region at $22 \mathrm{LT}$ and $00 \mathrm{LT}$. The data corresponding to $22 \mathrm{LT}$ are included to analyze the effect that vertical component field-aligned neutral wind $(V)$ has on $\mathrm{vTEC}_{\mathrm{GNSS}}$ at midnight. The vTEC $\mathrm{GNSS}_{\mathrm{G}}$ in all regions shows values lower at $00 \mathrm{LT}$ than at $22 \mathrm{LT}$, and these changes can be understood by taking into account the mean $V_{\mathrm{HWM} 07}$ variability.

Table 1 lists the mean difference values of vTEC between $22 \mathrm{LT}$ and $00 \mathrm{LT}$ in TECu and in percentages with respect to the mean value vTEC at $22 \mathrm{LT}$. The standard deviation of the mean difference values is shown, and the last column is the mean value of the vertical component of the field-aligned neutral wind at $22 \mathrm{LT}$, using all the data within each region shown in Fig. 2. Owing to the discrepancy shown by the wind models (David et al. 2014), it is difficult to establish a quantitative relationship between the wind value and the vTEC decrease. However, we can see that with a mean vertical wind of $18 \mathrm{~m} / \mathrm{s}$, there is a decrease of $8-11 \%$ in all regions except for
Oceania. In this region, the wind is lower, with a mean value of about $3 \mathrm{~m} / \mathrm{s}$, and the decrease in vTEC is slightly higher, reaching values of $13.4 \%$. Therefore, in all regions, the winds values are not strong enough to maintain the $F$ region density above the altitude range of recombination, because according to David et al. (2014), $V$ values of $80 \mathrm{~m} / \mathrm{s}$ (upward drift) are required.

PCA decomposition allows for the quantification of the contribution of each mode and enables identification of physically meaningful patterns in spatial and temporal variations. Table 2 lists the contributions of the first components for each data set and region. These few components represent more than approximately $95 \%$ of the total variance of the original data, so it is reasonable to use these modes as well as the associated principal components to describe the variations.

As explained in "Appendix," each mode can be written as the product $\left(\mathbf{a}_{\mathbf{i}} \cdot \mathbf{e}_{\mathbf{i}}^{\mathbf{T}}\right)$, where $\boldsymbol{e}_{\boldsymbol{i}}$ contains the spatial variation over each region, $\boldsymbol{a}_{\boldsymbol{i}}$ contains the temporal variation of the data set spanning 2000-2003, and $i$ is associated with the mode $(1,2$, or 3$)$. The units of the product of $\mathbf{a}_{\mathbf{i}}$ and $\mathbf{e}_{\mathbf{i}}$ are TECU ( 1 TECU $=10^{16}$ electron $\left./ \mathrm{m}^{2}\right)$ for $\mathrm{vTEC}_{\mathrm{GNSS}}$ or $\mathrm{vTEC}_{\mathrm{IRI}}$ and $\mathrm{m} / \mathrm{s}$ for $V_{\mathrm{HWM} 07}$. Equation (9) enables rewriting of the values of $\mathrm{vTEC}_{\mathrm{GNSS} / \mathrm{IRI}}$ and $V_{\mathrm{HWM} 07}$ variability for each mode as follows:

$$
\operatorname{mode}_{i}(t, x)=a_{i}(t) e_{i}^{\mathrm{T}}(x),
$$

for $i=1,2,3$, where $t$ is the day of the year, and $x$ is the latitude and longitude.

Consequently, to reconstruct the original signal with the modes that represent the major variability, $\mathrm{vTEC}_{\mathrm{GNSS} / \mathrm{IRI}}^{*}(t, x)$ data can be written as:

$$
\operatorname{vTEC}_{\mathrm{GNSS} / \mathrm{IRI}}^{*}(t, x)=\overline{\operatorname{vTEC}}_{\mathrm{GNSS} / \mathrm{IRI}}(x)+\sum_{i=1}^{3} a_{i}(t) e_{i}^{\mathrm{T}}(x)
$$

where $t$ is the day of the year, $x$ is the latitude and longitude, and $\overline{\operatorname{vTEC}}_{\text {GNSS/IRI }}(x)$ is the mean value of $\mathrm{vTEC}_{\mathrm{GNSS} / \mathrm{IRI}}$ for each $x$ location.

Global vTEC maps from IGS have an error of 4-5 TECU (Hernández-Pajares et al. 2009). Once the PCA technique is applied, the reconstruction using only a few modes has an error one order of magnitude lower than the original data errors. Therefore, the error of the PCA solution (Huang et al. 2005) is proportional to the data error and inversely proportional to the square root of the count of data over time (in our case, $365 * 3$ ); i.e., the error of our PCA results is approximately equal to (4-5) $\mathrm{TECu} * 0.03$.

To analyze the wind effect on vTEC variability, we applied the PCA technique on the vertical component of the field-aligned neutral wind $(V)$ obtained using the HWM07 model, $V_{\text {HWM07. }}$. 

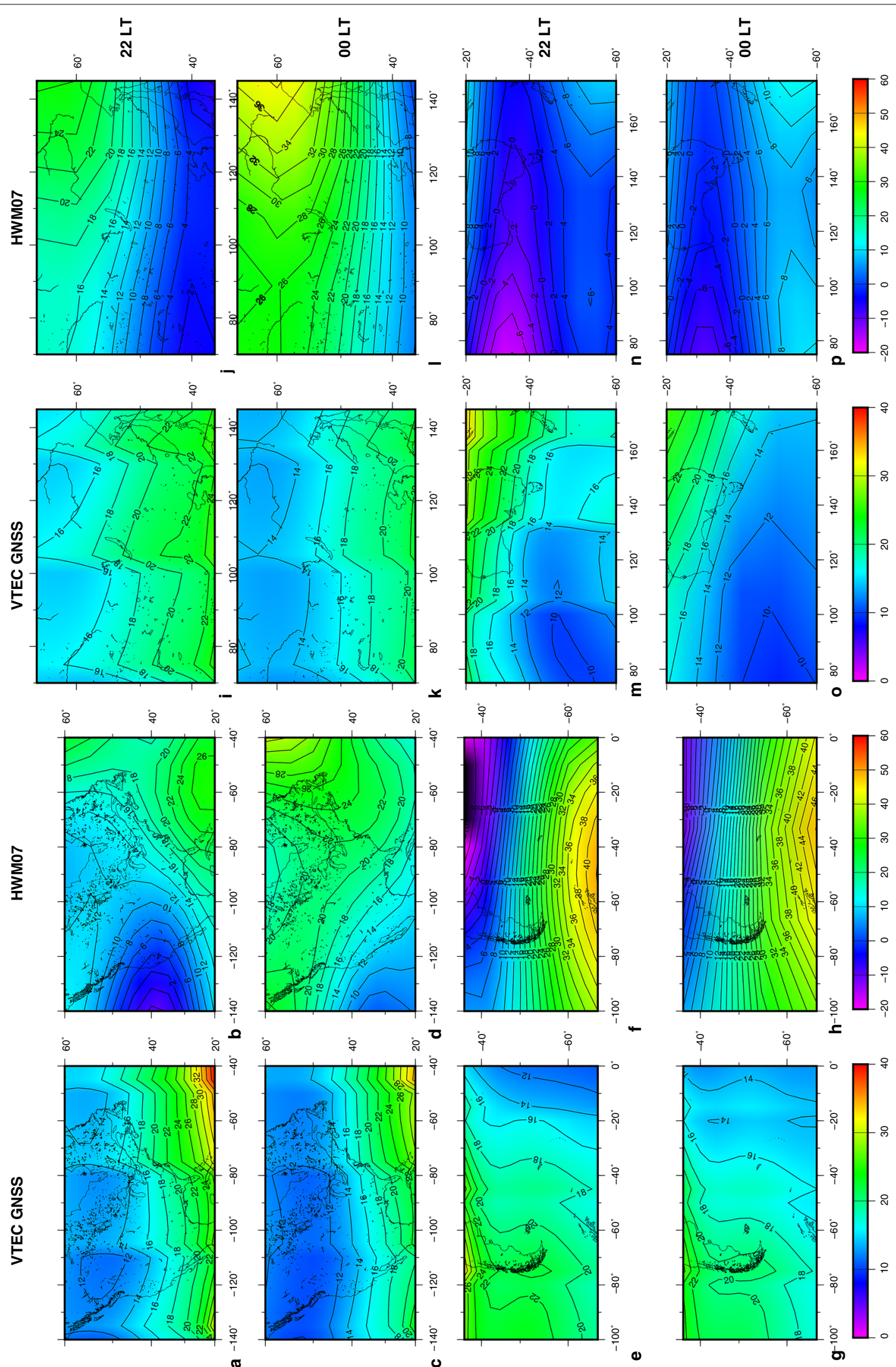

Fig. 2 Average values of $V T E C_{G N S S}$ for each region at $22 \mathrm{LT}$ (panels $\mathbf{a}, \mathbf{e}, \mathbf{i}$ and $\mathbf{m}$ ); at $00 \mathrm{LT}$ (panels $\mathbf{c}, \mathbf{g}, \mathbf{k}$ and $\mathbf{o}$ ). Average values of $V_{H W M 07}$ for each region at $22 \mathrm{LT}$ (panels $\mathbf{b}, \mathbf{f}, \mathbf{j}$ and $\mathbf{n}$ ); at $00 \mathrm{LT}$ (panels $\mathbf{d}, \mathbf{h}, \mathbf{I}$ and $\mathbf{p}$ ) 
Table 1 Mean difference values of vTEC between 22 LT and 00 LT in TECu and with respect to the mean value vTEC at 22 LT (in \%), standard deviation of the mean difference values, and mean value of the vertical component of the field-aligned neutral wind at $22 \mathrm{LT}$

\begin{tabular}{|c|c|c|c|}
\hline Region & 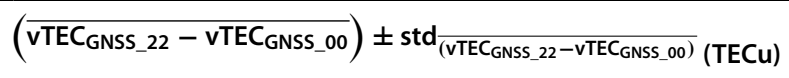 & With respect to $\overline{\text { vTEC GNSS_22 }}(\%)$ & $\overline{\overline{V_{\text {HWM07_22 }}}(\mathrm{m} / \mathrm{s})}$ \\
\hline North America & $2.11 \pm 0.03$ & 11.4 & 17.37 \\
\hline South America & $1.40 \pm 0.04$ & 7.6 & 18.33 \\
\hline Asia & $2.20 \pm 0.02$ & 11.6 & 17.84 \\
\hline Oceania & $2.30 \pm 0.03$ & 13.4 & 2.75 \\
\hline
\end{tabular}

These values were derived using all data within each region shown in Fig. 2

\section{PCA on VTEC GNSS $_{\text {S }}$}

Figures $3,4,5$, and 6 show the PCA applied on the vTEC $_{\text {GNSS }}$ over the North America, South America, Asia, and Oceania regions, respectively. The PCA modes are located in distinguished rows in each figure, and the last row shows the mean vTEC ${ }_{\text {GNSS }}$ spatial variation and the mean synthesized values of vTEC $_{\text {GNSS }}$ (Eq. 4) for each highlighted sector and its difference. The columns from left to right are ordered as follows: the amplitude (or temporal variation, $\left.\mathbf{a}_{\mathbf{i}}\right)$, spatial variation $\left(\mathbf{e}_{\mathbf{i}}\right)$, mean synthesized data for each mode over red (east) and blue (west) rectangles, and difference between red and blue curves. Table 3 provides the mean $\mathrm{vTEC}_{\mathrm{GNSS}}, V_{\mathrm{HWM} 07}$, and the east-west difference ( $\mathrm{dvTEC}_{\mathrm{GNSS}}$ and $\left.\mathrm{d} V_{\mathrm{HWM} 07}\right)$ values for each highlighted sector in all regions. Figures 7, 8, 9, and 10 show the PCA applied on $V_{\text {HWM07 }}$ to improve the interpretation of the influence of these winds on vTEC $_{\text {GNSS }}$ at night.

In the North American region (Fig. 3), the main vTEC variability (mode 1, Fig. 3a) is a strong annual variation, with the highest values occurring in the later March equinox and the lowest values occurring in the December solstice, with a semiannual component overlapped (and at maximum near the equinoxes). The spatial variation increases toward the lower latitudes, and its behavior is similar to the average values of $\mathrm{vTEC}_{\mathrm{GNSS}}$ (Fig. $3 \mathrm{~m}$ ). This variability is the result of the combined effect of the neutral composition, mean vertical wind, and the solar irradiation variations. The latter is related to the daytime electron density distribution, which is the starting condition before beginning the nighttime loss processes. The second highlighted feature (mode 2, Fig. 3e, f) is a strong latitudinal variation, where the values are positive for latitudes higher than $40^{\circ}-45^{\circ}$ and negative for latitude lower than $40^{\circ}-45^{\circ}$ during the December solstice, with opposite behavior occurring during the equinoxes; however, this mode does not contribute during the June solstice. This seasonal variation could be related to the winter anomaly at higher mid-latitudes (Rishbeth 1998). This ionospheric anomaly is enhanced at high solar activity during daytime hours (Jee et al. 2004). We also see this effect during nighttime hours, and thus, hereafter, we name this behavior "the remnant of the winter anomaly" Finally, the third mode contribution shows a larger vTEC $_{\text {GNSS }}$ variation at the east coast than the west coast from September and April (Fig. 3i, j), correlated with the $V_{\text {HWM07 }}$ variability represented in its first PCA mode (Fig. 7a, b). Their values are negative, but are lower at the western coast than at the eastern coast for the same time period, producing a greater loss of electron in the west coast. The longitudinal anomaly (east-west difference) can be explained with a higher mean value of $\mathrm{vTEC}_{\mathrm{GNSS}}$ for the eastern coast during the 3 years (Table 3), with the influence of mode 1 (Fig. 3a, b) and mode 3 (Fig. 3i, j) contributing to a higher positive difference in the March equinox but close to zero during the December solstice (Fig. 3o). Similar results were found by Zhang et al. (2011,2013), Xu et al. (2013), and Chen et al. (2015).

In the South American region (Fig. 4) the main variability (mode 1, Fig. 4a) is a strong annual variation,

Table 2 Percentage of variability for each data set and region

\begin{tabular}{|c|c|c|c|c|c|c|c|c|}
\hline \multirow[t]{2}{*}{ Region } & \multicolumn{3}{|l|}{ vTEC $_{\text {GNSS }}$} & \multicolumn{2}{|l|}{$\mathrm{vTEC}_{\text {IRI }}$} & \multicolumn{3}{|l|}{$V_{\text {HWM07 }}$} \\
\hline & Mode $1(\%)$ & Mode 2 (\%) & Mode 3 (\%) & Mode 1 (\%) & Mode $2(\%)$ & Mode 1 (\%) & Mode 2 (\%) & Mode $3(\%)$ \\
\hline North America & 87 & 5 & 2.3 & 90 & 7 & 91 & 5.7 & 2.8 \\
\hline South America & 94 & 3.5 & 1 & 95 & 3.9 & 60 & 27 & 11 \\
\hline Asia & 91 & 4.3 & 1.3 & 98 & 1 & 85 & 9.6 & 4.7 \\
\hline Oceania & 93 & 2.8 & 1 & 97 & 1.7 & 50 & 33 & 16 \\
\hline
\end{tabular}



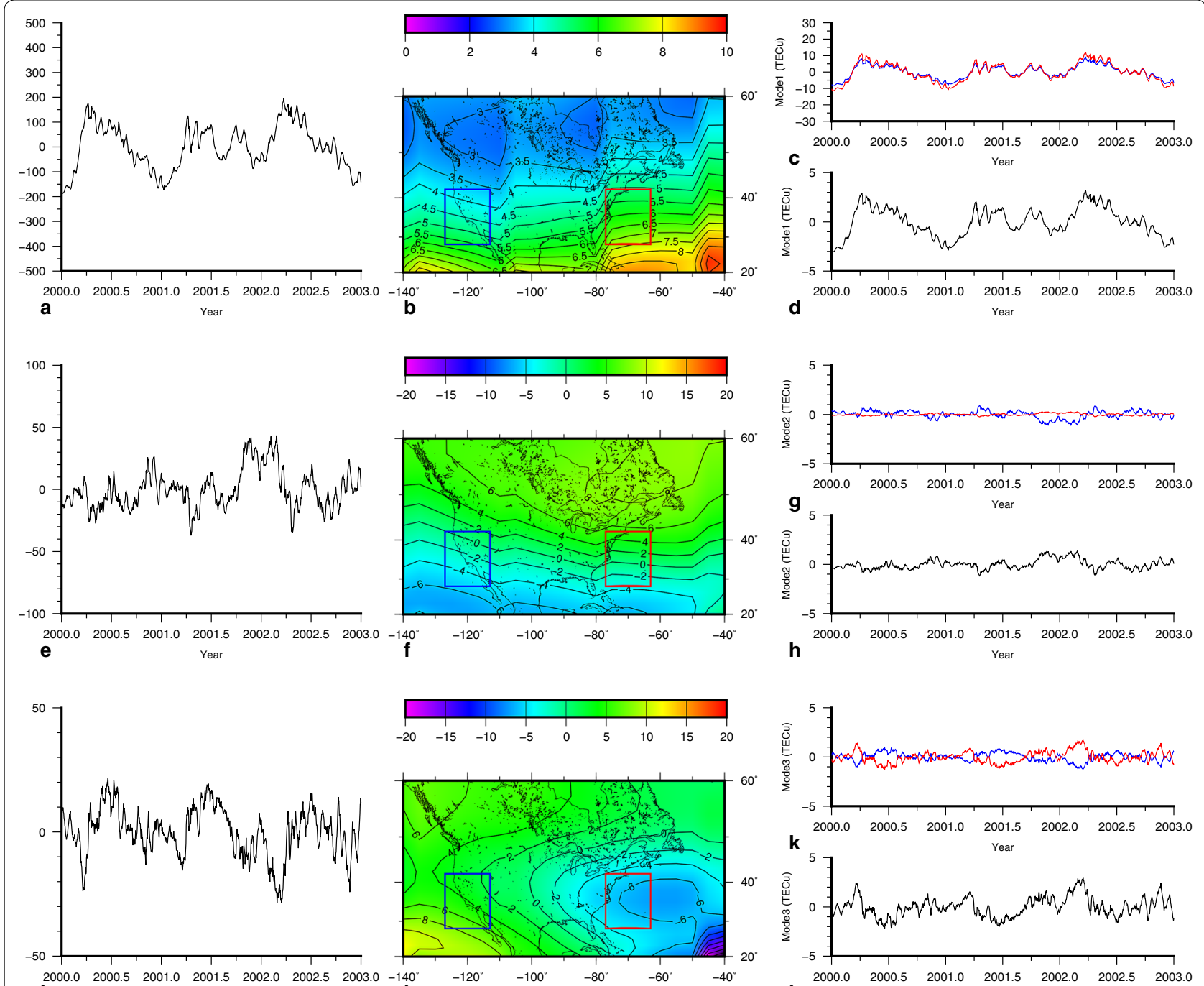

h
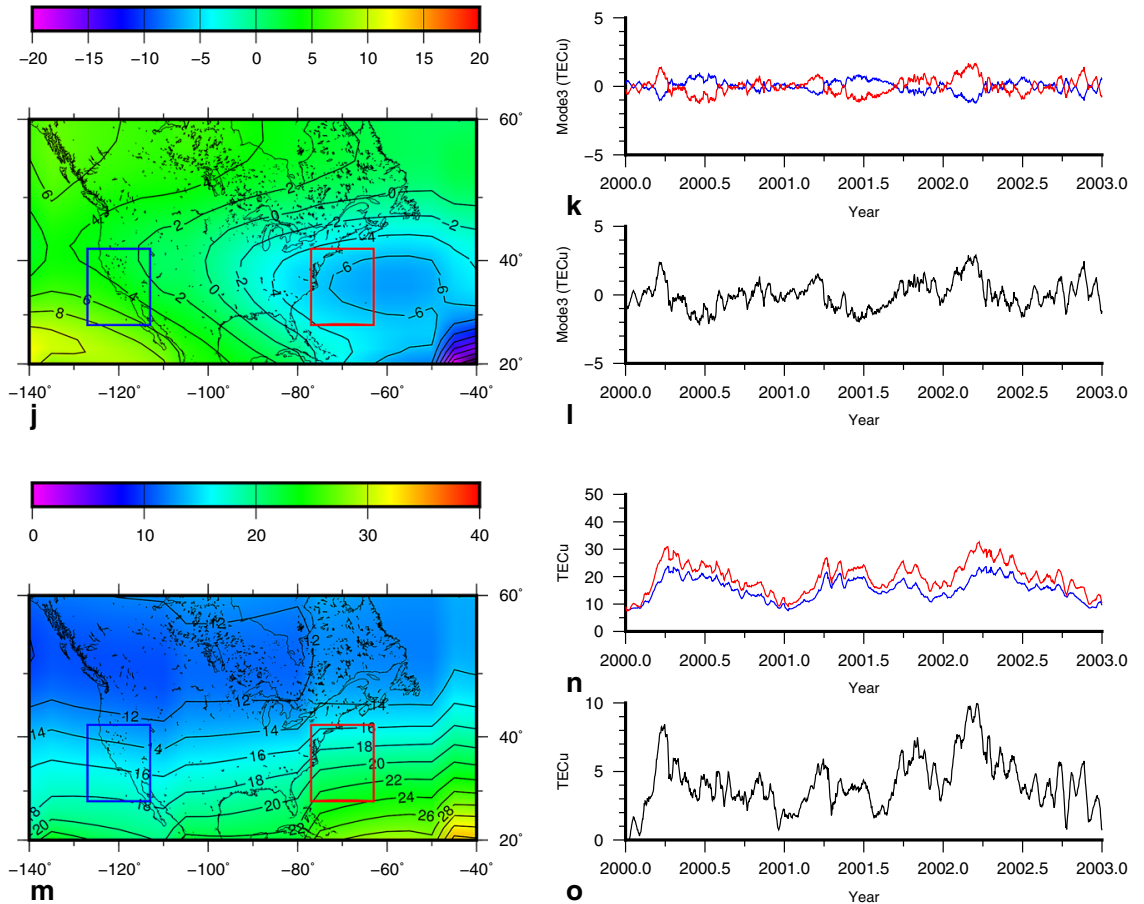

Fig. $3 V_{T E C_{G N S S}}$ over the North American region: a amplitude of the temporal variation, $a_{1}$ (the $y$-axis has to be multiplied by a factor of $10^{-2}$ ), $\mathbf{b}$ eigenvector or spatial variation, $e_{1}$, c synthesized data for mode $1\left(a_{1} \cdot e_{1}^{\top}\right)$ for red (east) and blue (west) rectangles, $\mathbf{d}$ difference between red and blue curves of $\mathbf{c}, \mathbf{e}$ the amplitude of the temporal variation, $a_{2}$ (the $y$-axis has to be multiplied by a factor of $10^{-2}$ ), $\mathbf{f}$ eigenvector or spatial variation, $e_{2}, \mathbf{g}$ synthesized data for mode $2\left(a_{2} \cdot e_{2}^{\top}\right)$ for red (east) and blue (west) rectangles, $\mathbf{h}$ difference between red and blue curves of $\mathbf{g}$, $\mathbf{i}$ the amplitude of the temporal variation, $a_{3}$ (the $y$-axis has to be multiplied by a factor of $\left.10^{-2}\right)$, $\mathbf{j}$ eigenvector or spatial variation, $e_{3}, \mathbf{k}$ synthesized data for mode $3\left(a_{3} \cdot e_{3}^{\top}\right)$ for red (east) and blue (west) rectangles, and $\mathbf{I}$ difference between red and blue curves of $\mathbf{k}$. Finally, the time-averaged $\overline{v T E C}_{G N S S}(x)(\mathbf{m})$, the synthesized data, $\mathbf{n} \overline{\operatorname{TTCC}}_{\mathrm{GNSS}}^{*}(t)$, for red (east) and blue (west) rectangles, and the difference $\left(\overline{\mathrm{dvTEC}}_{\mathrm{GNSS}}^{*}(t)\right)$ between red and blue curves of $\mathbf{n}(\mathbf{o})$ 

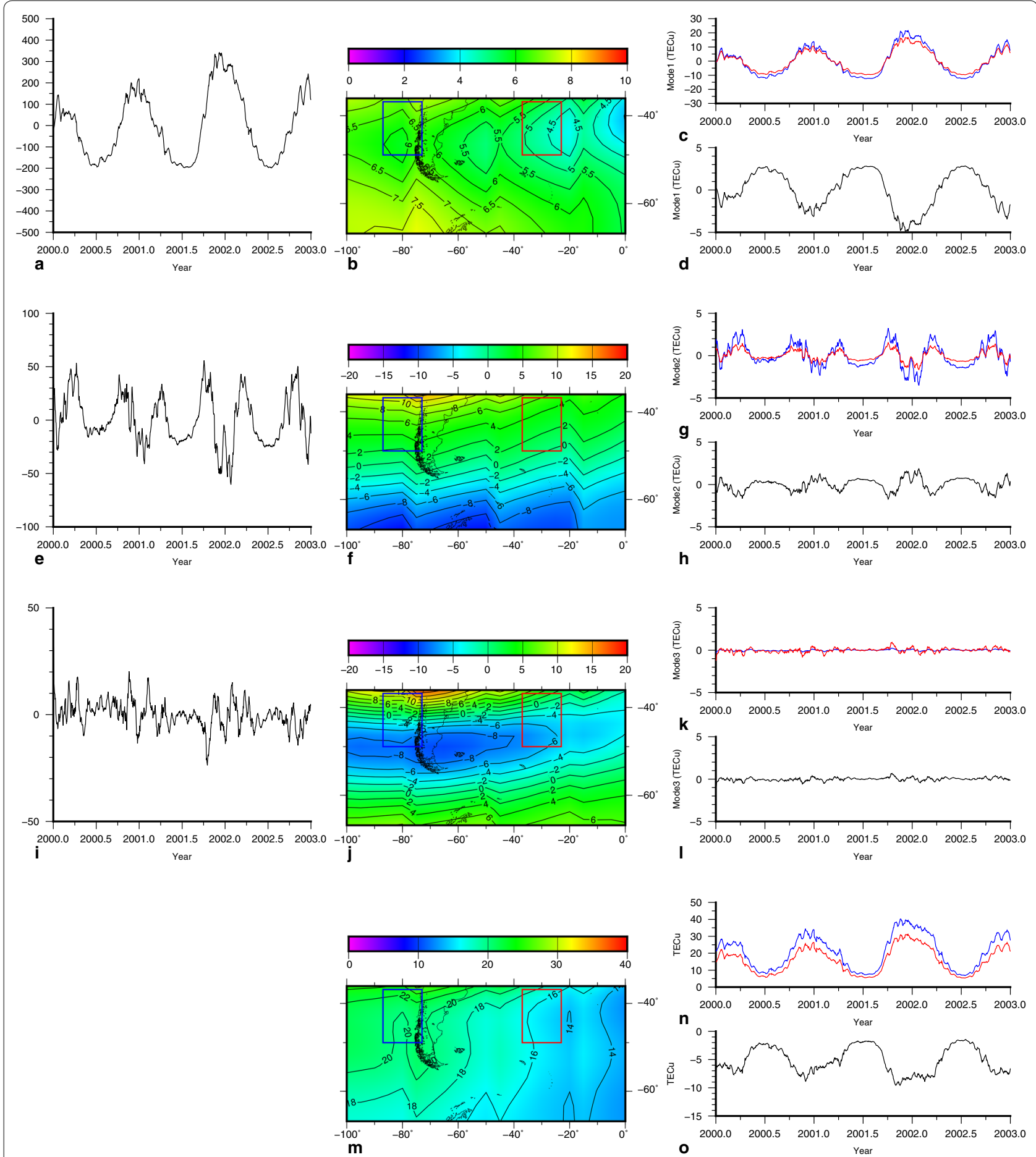

Fig. 4 Idem Fig. 3 for the South American region

with the highest values occurring in the December solstice and the lowest values occurring in the June solstice. During the December solstice, the minimum values are located between -40 and -55 latitude, increasing at higher and lower latitudes and from east to west (Fig. 4b); the opposite occurs during the June solstice. This first mode describes the vTEC $_{\text {GNSS }}$ variability, caused by the combined effect of the neutral composition, mean 

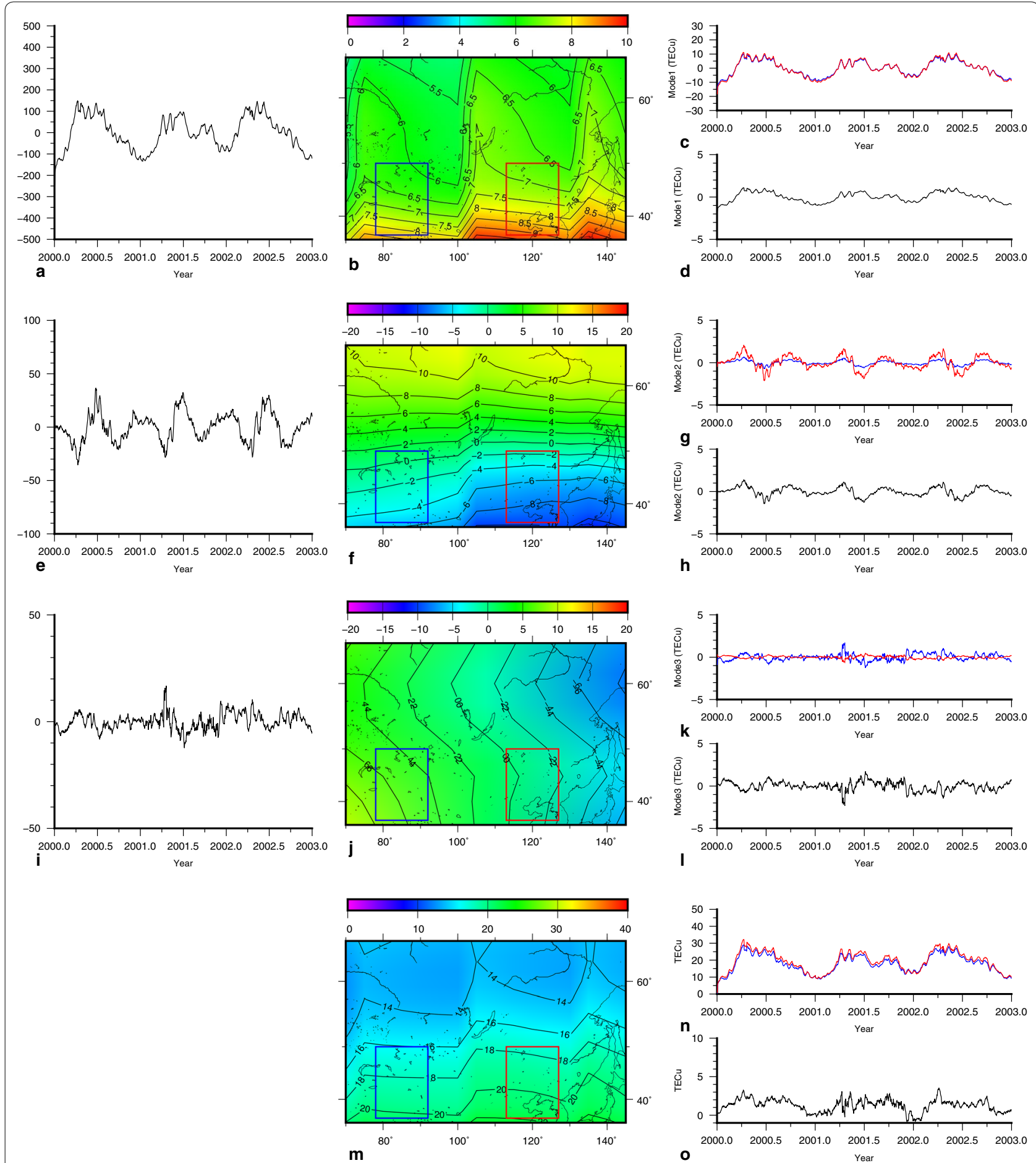

Fig. 5 Idem Fig. 3 for the Asian region

vertical wind, the solar irradiation variations (which define the starting conditions before beginning the nighttime loss processes), and the first two modes of $V_{\mathrm{HWM} 07}$. The more significant feature in the second mode (Fig. 4e, f) is the strong latitudinal variation; the values are positive for latitudes higher than $-50^{\circ}$ and negative for lower latitudes during the equinoxes; the opposite occurs during solstices. Figure 8 shows the $V_{\text {HWM07 }}$ PCA results. 

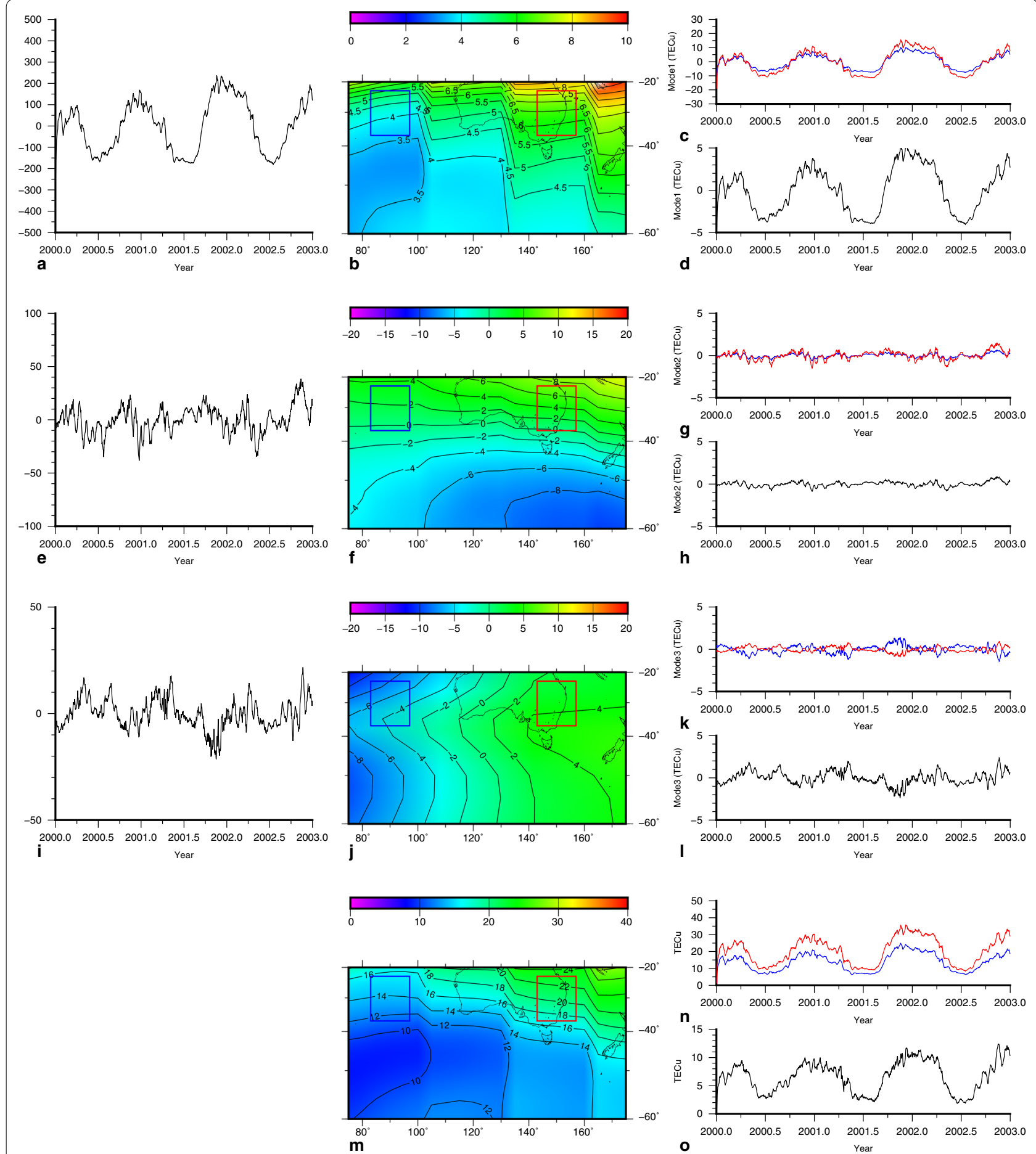

Fig. 6 Idem Fig. 3 for the Oceania region

The first and second modes play an important role in describing its variability (Table 2 ). Figure $8 \mathrm{a}$, b shows an annual variation with a semiannual component overlapped, with positive increasing $V_{\text {HWM07 }}$ toward higher latitudes during the December solstice. This variation drives higher vTEC $_{\text {GNSS }}$ values at mid-high latitudes during the December solstice, and this result is shown in the

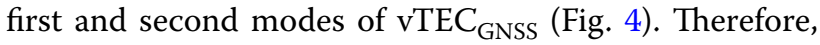


Table 3 Mean values of vTEC $_{\mathrm{GNSS}}, \boldsymbol{V}_{\mathrm{HWM07}}$, and the east-west difference, $\mathrm{dvTEC}$ GNSs, and $\mathrm{d} V_{\mathrm{HWM07}}$, at 00 LT for the highlighted sectors in the four regions

\begin{tabular}{|c|c|c|c|c|c|c|}
\hline \multirow[t]{2}{*}{ Region } & \multicolumn{2}{|c|}{$\overline{\mathrm{vTEC}}_{\mathrm{GNSS}}(\mathrm{TECu})$} & \multicolumn{2}{|c|}{$\bar{V}_{\text {HWM07 }}(\mathrm{m} / \mathrm{s})$} & \multirow[t]{2}{*}{$\mathrm{dvTEC}_{\mathrm{GNSS}}(\mathrm{TECu})$} & \multirow[t]{2}{*}{$\mathrm{d} V_{\text {нWм07 }}(\mathrm{m} / \mathrm{s})$} \\
\hline & East & West & $\overline{\text { East }}$ & West & & \\
\hline North America & 19.7 & 15.6 & 22.3 & 12.3 & 4.1 & 10 \\
\hline South America & 15.7 & 20.8 & 5.7 & 15.8 & -5.1 & -10 \\
\hline Asia & 19.3 & 18 & 18.8 & 17 & 1.3 & 1.8 \\
\hline Oceania & 20.0 & 13.7 & -0.4 & -6.5 & 6.3 & 6.1 \\
\hline
\end{tabular}

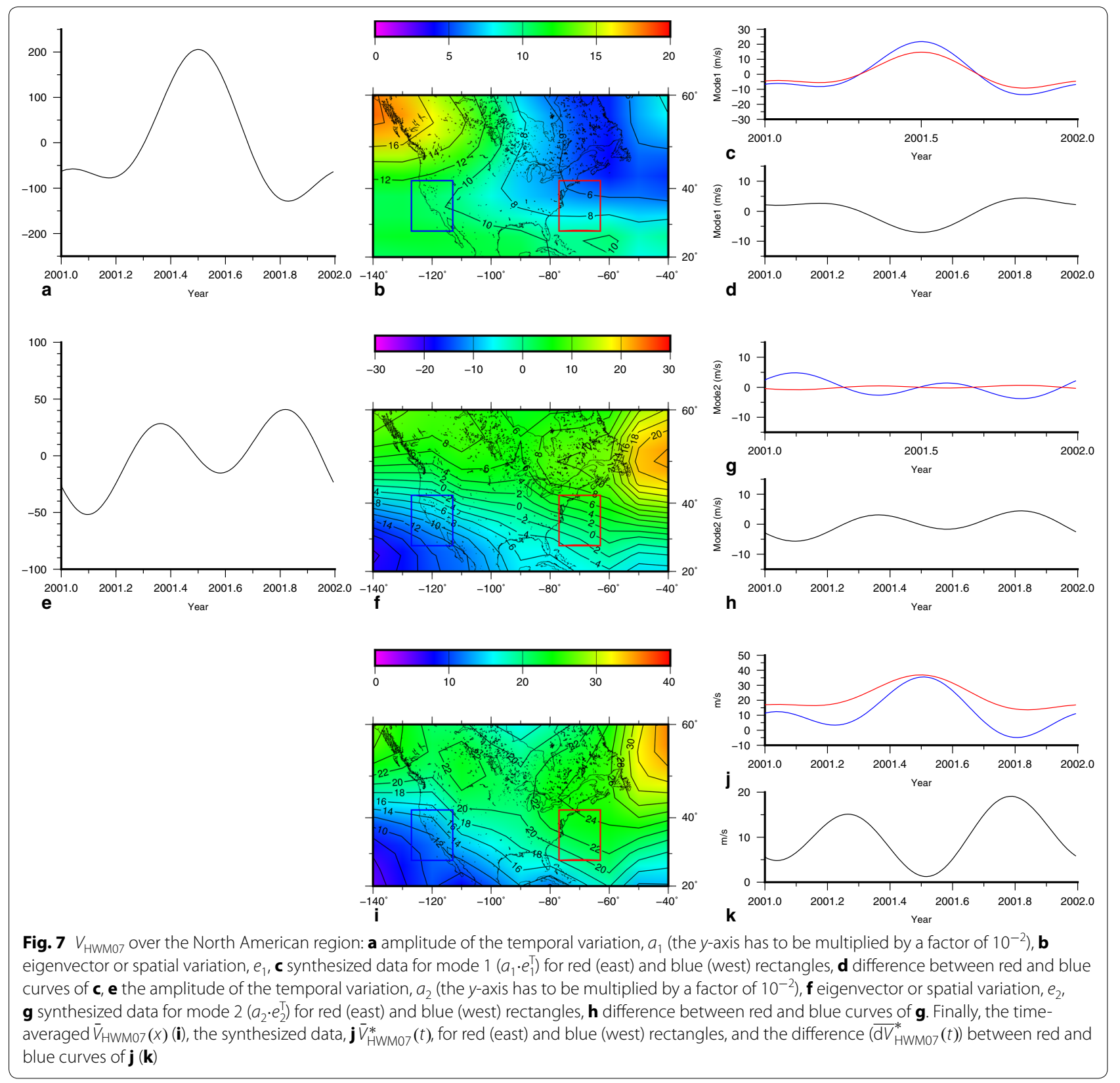











the combined contribution of modes 1 and 2 describes a maximum $\mathrm{vTEC}_{\mathrm{GNSS}}$ variation toward mid-high latitudes during the summer, related to the MSNA (Lin et al. 2010; Jee et al. 2009; Meza et al. 2015). This highlights the second feature mentioned by Thampi et al. (2009), where the electron density at mid-latitude remains higher than that at lower latitudes.

Our results also show an east-west difference in the South America region. The longitudinal anomaly can be explained by a higher mean value of $\mathrm{vTEC}_{\mathrm{GNSS}}$ for the western side over the 3-year period (Table 3 ) and the contribution of modes 1 and 2; they show a higher difference in both the equinoxes and in summer (Fig. 4o). The variation in $\mathrm{vTEC}_{\mathrm{GNSS}}$ can be related to the negative mean value of the east-west difference of $V_{\mathrm{HWM} 07}$ (Fig. 8m) and the contribution of the PCA mode on $V_{\mathrm{HWM} 07}$ (Fig. $8 \mathrm{i}$, j). Xu et al. (2013) analyzed the longitudinal anomaly in South America at different local times from 2001 to 2010 and found negative values for the east-west difference, with larger values during December and lower ones during June; our results are similar.

In the Asia region (Fig. 5), the main variability (mode 1 , Fig. 5a) is a strong annual variation, with the highest values occurring in the later March equinoxes and the lowest values in the December solstices, with a semiannual component overlapped (and at maximum near the equinoxes). The vTEC $_{\mathrm{GNSS}}$ increases toward the lower latitudes, and its behavior is analogous to the average val-

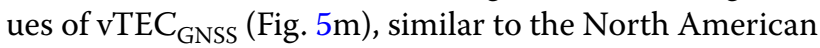
region. 

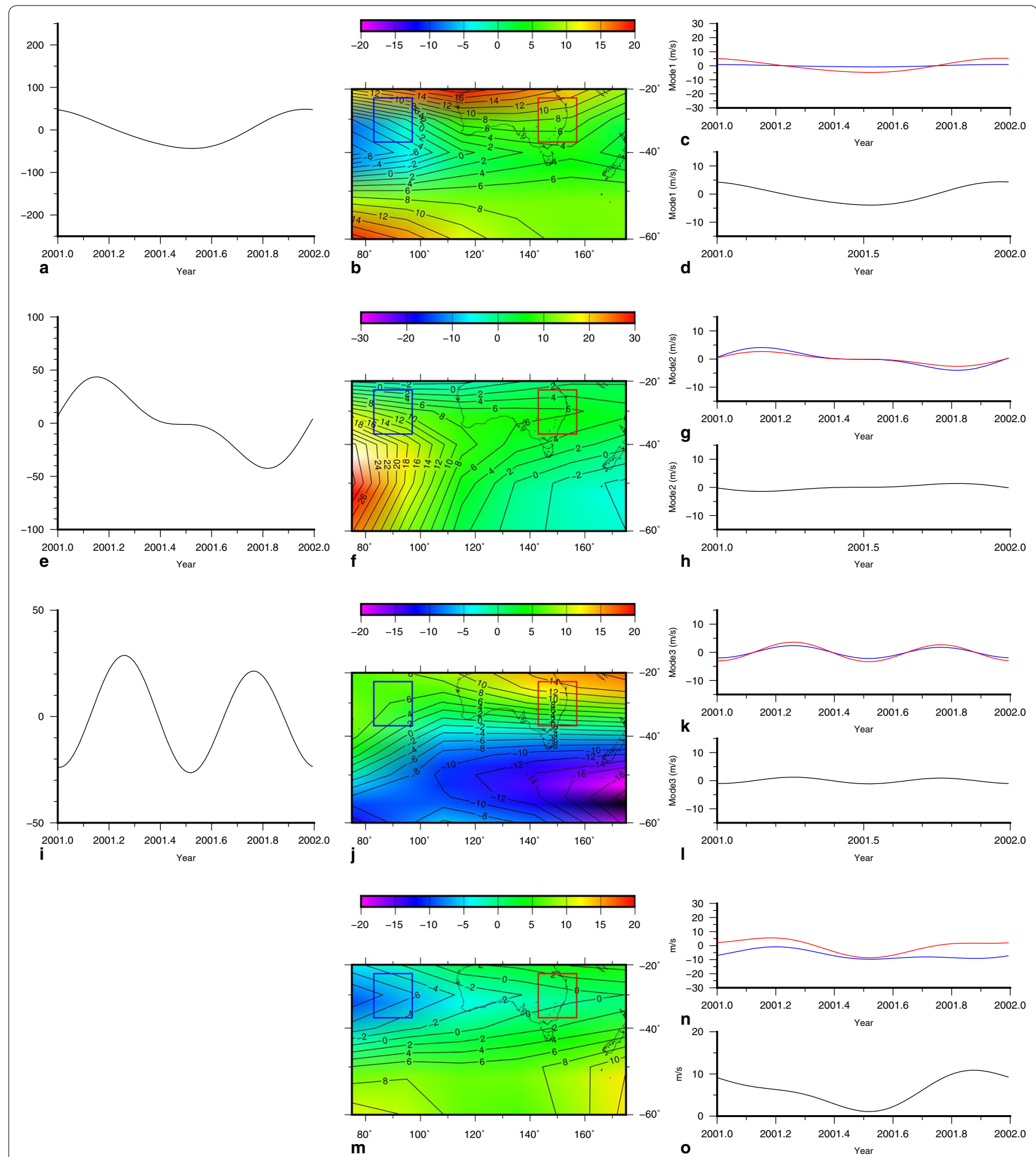

Fig. 10 Idem Fig. 8 for the Oceania region

The second important feature (mode 2, Fig. 5f) is a strong latitudinal variation. During solstices the vTEC $_{\text {GNSS }}$ variability is positive at latitudes higher than $50^{\circ}$ (larger in June than during the December solstice), the opposite of what happened during the equinoxes. The combined contribution of mode 1 (Fig. 5a, b) and mode 2 (Fig. $5 \mathrm{e}, \mathrm{f}$ ) describes why vTEC $_{\text {GNSS }}$ values are slightly higher toward mid-high latitudes during the June 
solstice. This could be related to the MSNA as its appearance is weak, and similar results have been obtained by others (Lin et al. 2010), especially in a region centered at $135^{\circ} \mathrm{E}$, where those authors worked (Fig. 6 in Lin et al. 2010). Analyzing the $V_{\mathrm{HWM} 07} \mathrm{PCA}$ results, the first mode (Fig. 9a, b) shows large positive values at the southwestern side during the June solstice, decreasing to the eastern side, and in the eastern side, the values increase toward the north. This can be related to the second mode

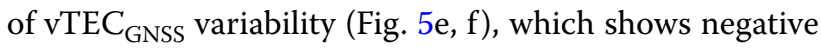
$\mathrm{vTEC}_{\mathrm{GNSS}}$ variation at latitudes lower than $50^{\circ}$ during the solstices, and is larger toward the eastern side than the western.

The longitudinal anomaly can be explained by a slightly higher mean value of $\mathrm{vTEC}_{\mathrm{GNSS}}$ to the east than the west during the 3-year period (Table 3) and by the contributions of modes 1 and 2, which show a weak positive difference during the equinoxes and a weak negative difference during the solstices (Fig. 5o); this is related to the $V_{\text {HWM07 }}$ behavior (Fig. $9 \mathrm{k}$ ).

In the Oceania region (Fig. 6), the main variability (mode 1, Fig. 6a) is an annual variation, with the highest values occurring during the December solstice. The vTEC $_{\text {GNSS }}$ increases toward lower latitudes and toward the east, and its behavior is analogous to the average values of $\mathrm{vTEC}_{\text {GNSS }}$ (Fig. $6 \mathrm{~b}, \mathrm{~m}$ ). This variability is caused by the combined effect of the neutral composition and the solar irradiation variations (which define the starting condition before beginning the nighttime loss processes). The second important feature (mode 2, Fig. 6e, f) is a strong latitudinal variation, where the $\mathrm{vTEC}_{\mathrm{GNSS}}$ variation is positive for mid-high latitudes $\left(-40^{\circ}\right.$ to $\left.-60^{\circ}\right)$ during the solstices; the opposite behavior occurs during the equinoxes. Similar to the North America region, this seasonal variation with the first PCA mode contribution can be related to the remnant of the winter anomaly at higher mid-latitudes.

The first, second, and third modes on $V_{\text {HWM07 }}$ (Fig. 10) can be correlated with the third PCA mode on vTEC ${ }_{G N S S}$. The longitudinal anomaly can be explained by a higher mean value of $\mathrm{vTEC}_{\mathrm{GNSS}}$ for the eastern side over the 3 -year period (Table 3) and the contribution of modes 1 and 3, showing a higher difference from September to April, especially during the December solstice (Fig. 6o).

\section{PCA on the IRI model}

The IRI 2012 model provides monthly averaged ionospheric parameters for magnetically quiet conditions. The model is constructed from both satellite and groundbased observations.

Figures 11, 12, 13, and 14 show the PCA applied to the vTEC $_{\text {IRI }}$ over the North America, South America, Asia, and Oceania regions, respectively. The organization of these figures is similar to those for $\mathrm{vTEC}_{\mathrm{GNSS}}$. Comparing the two PCAs, on vTEC $\mathrm{GNSS}_{\text {and }}$ vTEC $\mathrm{IRI}_{\mathrm{I}}$, some similarities and discrepancies appear, described below.

For all regions, the mean values of vTEC $_{\text {IRI }}$ (Figs. 11i, 12i, 13i, 14i) are lower (Table 4) than those obtained from vTEC $_{\text {GNSS }}$ for similar spatial variations.

In North America, the main variability (mode 1, Fig. 11a) is a strong annual variation with a maximum in March-June. The vTEC ${ }_{\text {IRI }}$ variation (Fig. 11b) increases toward lower latitudes during the June solstice, and the opposite occurs during the December solstice. There is no evidence of semiannual variation or winter anomaly. The second important feature is a longitudinal variation in vTEC $\mathrm{VRI}_{\text {IRI }}$ (Fig. 11f), with larger values at the east coast than the west coast during both equinoxes, higher in April. This pattern is similar to that observed in the third PCA mode of $\mathrm{vTEC}_{\mathrm{GNSS}}$. The longitudinal anomaly can be explained by a higher mean value of $\mathrm{vTEC}_{\text {IRI }}$ for the eastern coast over the 3 -year period (Table 3 ) and the main contribution of mode 2 . Contrary to the results for vTEC $_{\mathrm{GNSS}}$, the contribution of the first mode is insignificant and shows a higher difference during the equinoxes (Fig. 11k).

In the South America region, the main variability (mode 1, Fig. 12a) is a strong annual variation, with maximum values occurring during the December solstice located in a region centered approximately at $-60^{\circ}$ in latitude and $-70^{\circ}$ in longitude and decreasing radially (Fig. 12a, b). The other important feature in the second mode is the strong latitudinal variation (Fig. 12e, f) between longitudes $-50^{\circ}$ and $-100^{\circ}$; the values are positive for latitudes higher than $-50^{\circ}$ and negative for lower latitudes during the equinoxes, and the opposite occurs during the solstices. Therefore, at latitudes lower than $-50^{\circ}$, the $\mathrm{vTEC}_{\mathrm{IRI}}$ variation is positive during the solstices (Fig. 12f). The combined contribution of

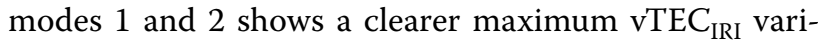
ation toward mid-high latitudes than that described by the MSNA (Hsu et al. 2011). The longitudinal anomaly can be explained by a higher mean value of $\mathrm{vTEC}_{\mathrm{IRI}}$ in the western coast during the 3 -year period (Table 3 ) and the contribution of mode 2. Contrary to the results for $\mathrm{vTEC}_{\mathrm{GNSS}}$, the contribution of the first mode is insignificant and shows a higher difference during both equinoxes (Fig. 12k).

In the Asia region, the main variability (mode 1, Fig. 13a) is a strong annual variation, with the highest values occurring during the June solstice, with a strongly latitudinal variation (Fig. 13b), increasing toward lower latitudes. The second mode (Fig. 13f) shows a positive variation at latitudes higher than $40^{\circ}$ during solstices 
(larger in June than in December); the opposite happened during the equinoxes (Fig. 13e, f). There is a weak longitudinal anomaly, and it can only be explained by a slightly higher mean value of $\mathrm{vTEC}_{\mathrm{IRI}}$ for the eastern coast during the 3-year period (Table 3), as the contributions of mode 1 and 2 are nearly zero (Fig. 13k). Although the values of the longitudinal anomaly are small (as was the case with vTEC $_{\text {GNSS }}$ ), a seasonal variation cannot be distinguished.

In Oceania, the main variability (mode 1, Fig. 14a) is an annual variation, with the highest values occurring during the December solstice. The spatial variation increases toward lower latitudes and toward the east (Fig. 14b), and its behavior is similar to $\mathrm{vTEC}_{\mathrm{GNSS}}$ (Fig. 6b). The contribution of the second mode is very small. The vTEC $\mathrm{VRI}_{\text {IRI }}$ variation increases to the east during the equinoxes (Fig. 14e, f). There is no evidence of a winter anomaly. The longitudinal anomaly can be explained by a higher mean value of $\mathrm{vTEC}_{\mathrm{IRI}}$ for the eastern coast during the 3 -year period (Table 3) and the contribution of mode 1 . A higher difference is shown during the December solstice and the equinoxes (Fig. 14k), and these results are similar to those of $\mathrm{vTEC}_{\mathrm{GNSS}}$.
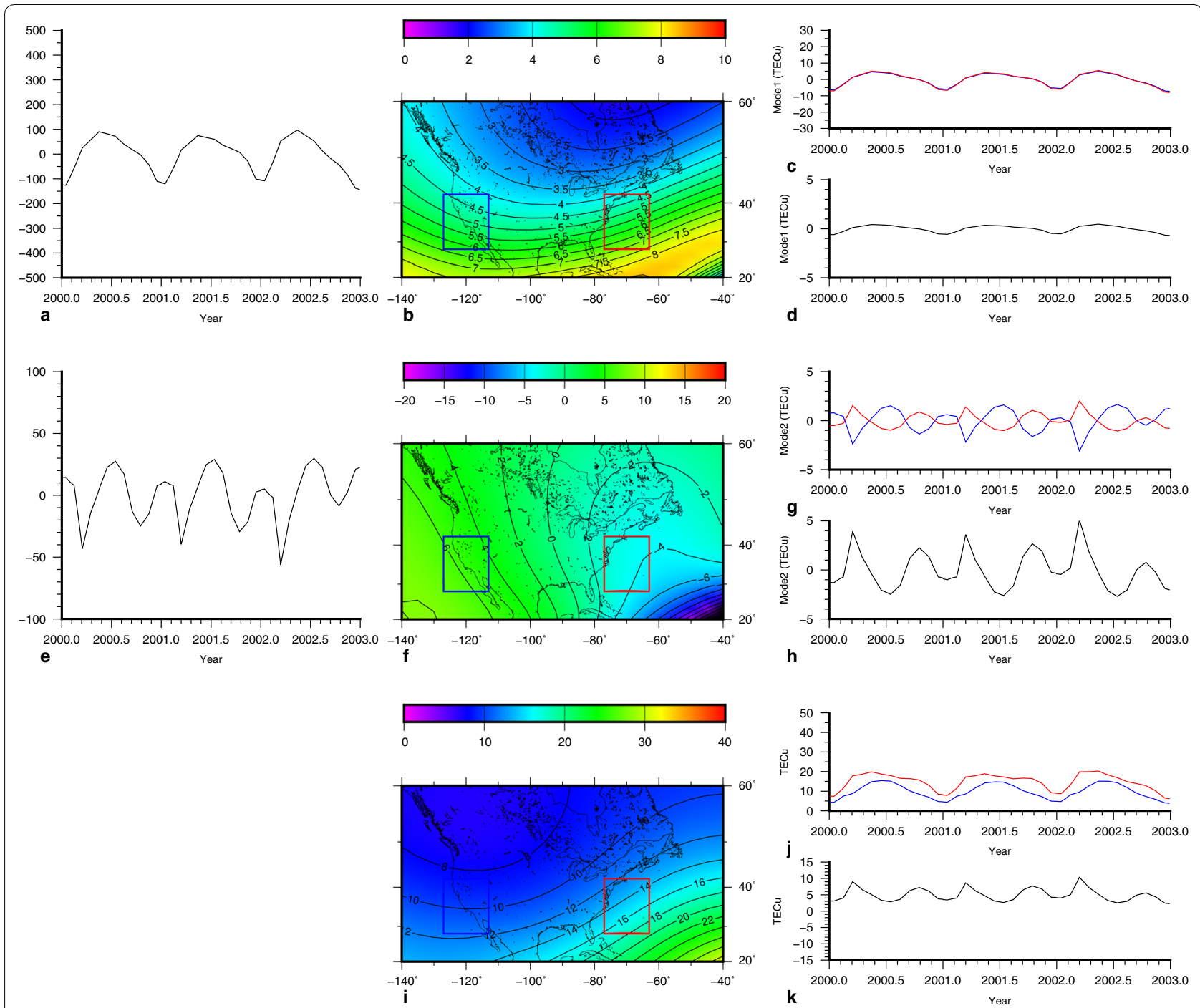

Fig. $11 \vee T E C_{|R|}$ over the North American region: a amplitude of the temporal variation, $a_{1}$ (the $y$-axis has to be multiplied by a factor of $10^{-2}$ ), $\mathbf{b}$ eigenvector or spatial variation, $e_{1}$, c synthesized data for mode $1\left(a_{1} \cdot e_{1}^{\top}\right)$ for red (east) and blue (west) rectangles, $\mathbf{d}$ difference between red and blue curves of Fig. 11c; $\mathbf{e}$ the amplitude of the temporal variation, $a_{2}$ (the $y$-axis has to be multiplied by a factor of $10^{-2}$ ), $\mathbf{f}$ eigenvector or spatial variation, $e_{2}, \mathbf{g}$ synthesized data for mode $2\left(a_{2} \cdot e_{2}^{\top}\right)$ for red (east) and blue (west) rectangles, $\mathbf{h}$ difference between red and blue curves of Fig. $11 \mathrm{~g}$. Finally, the time-averaged $\overline{v T E C}_{|R|}(x)(\mathbf{i})$, the synthesized data, $\mathbf{j} \overline{v T E C}_{|R|}^{*}(t)$, for red (east) and blue (west) rectangles, and the difference $\left(\overline{d v T E C}_{|R|}^{*}(t)\right)$ between red and blue curves of Fig. $11 \mathrm{j}(\mathbf{k})$ 

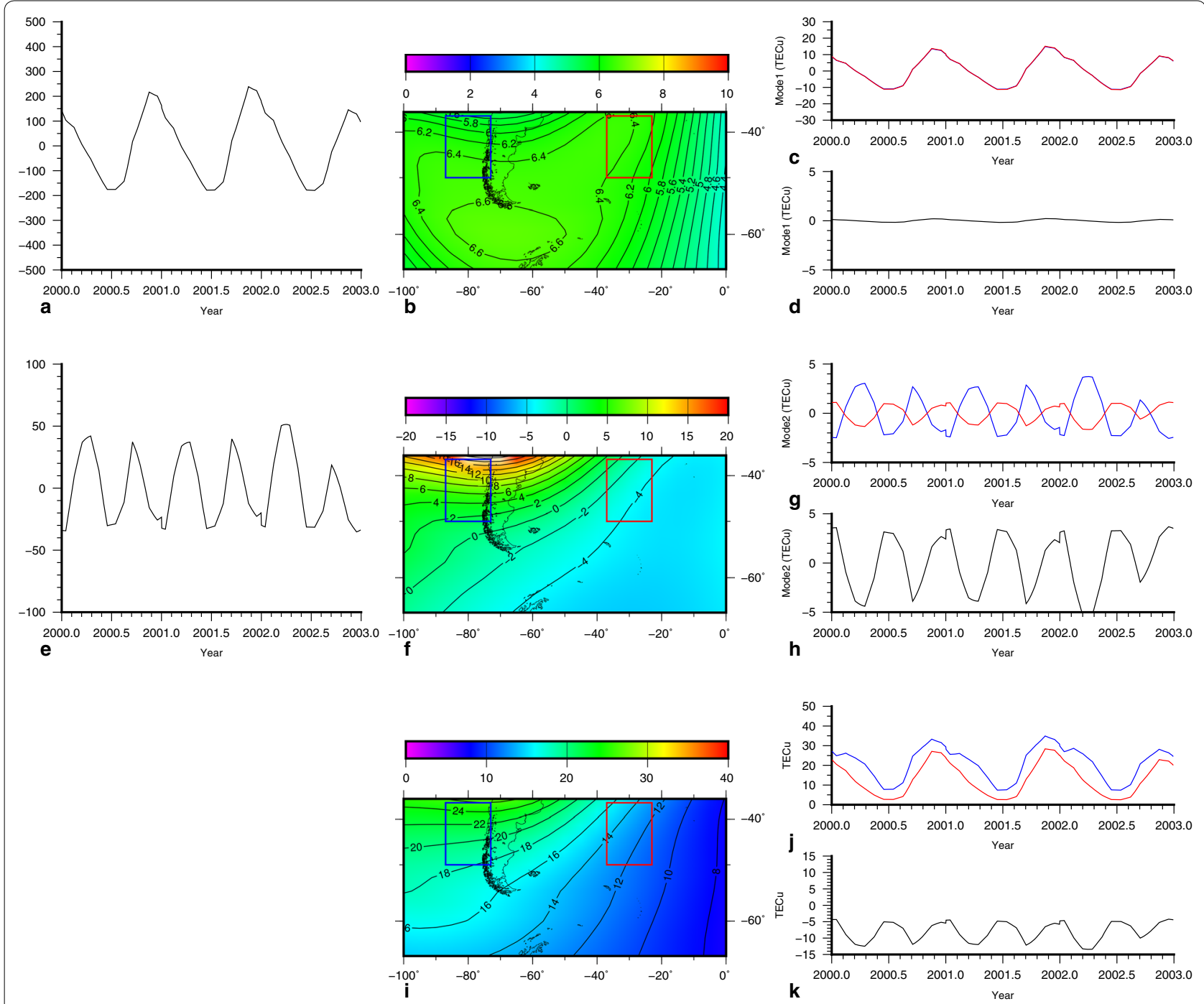

Fig. 12 Idem Fig. 11 for the South American region

\section{Discussion and conclusions}

We studied the effect of the thermospheric vertical neutral wind on vTEC variations, including longitudinal anomaly, remaining winter anomaly, MSNA, and semiannual anomaly at different mid-latitudes regions around zero magnetic declination at midnight during high solar activity.

First, at midnight the behavior of mean vTEC ${ }_{\text {GNSS }}$ values responds to vertical wind variation, experiencing a decrease of about $10 \%$ with the action of the positive vertical wind lasting for $2 \mathrm{~h}$ in all regions except Oceania. There, the situation is quite different, with values reaching up to $15 \%$ with almost no vertical wind. Hence, the vertical component of the field-aligned neutral wind $(V)$ is not strong enough to maintain electron density above the altitude range of recombination because the wind velocity is less than $80 \mathrm{~m} / \mathrm{s}$ (David et al. 2014).

The MSNA has been extensively studied by others (Horvath and Essex 2003; Horvath 2006; Lin et al. 2010). All agree that this feature is more intensive during low solar activity and near the Weddell Sea. Our results showed that, in South America and Asia, a maximum vTEC $_{\text {GNSS }}$ variation toward mid-high latitudes during summer is related to the MSNA, and it is weaker in the Asian region (Lin et al. 2009). This agrees with the main vertical wind variability, as described in "Results" section. Therefore, we support the belief that the thermospheric wind is one of the most important components of the MSNA (Lin et al. 2009; Thampi et al. 2009). 


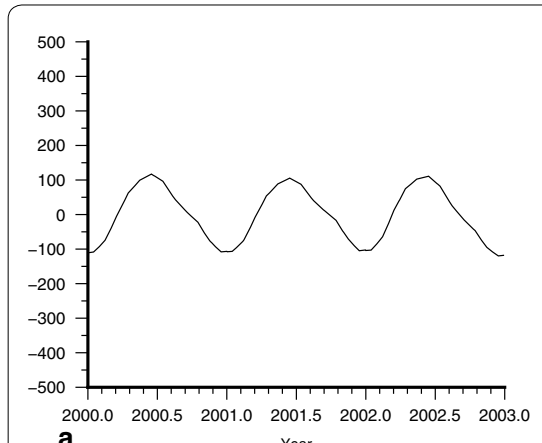

a $\quad$ Year

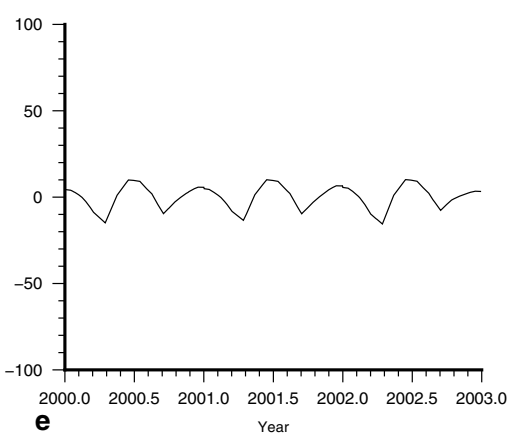

Year

The winter anomaly in the F2 region is defined as the condition in which a greater daytime electron density is seen at the F2 peak in winter than in summer (Burns et al. 2014; Rishbeth and Garriot 1969). This anomaly is primarily due to greater winter to summer differences of [O]/[N2] at solar maximum than at solar minimum for daytime hours. When we see this effect during nighttime hours, we call it the remnant of the winter anomaly. This effect was observed in North America and Oceania, at a similar magnitude for both regions.

It is worth noting that these two anomalies, namely the MSNA and the remnant of the winter anomaly, are confined to different regions. We will try to explain why we see the MSNA in Asia and South America but not in North America nor Oceania, and vice versa for the remnant of the winter anomaly. As mentioned previously, the winter anomaly is principally due to an enhancement of the $[\mathrm{O}] /[\mathrm{N} 2]$ ratio that is related to the circulation processes in the thermosphere. The composition change is a result of the summer hemisphere being heated and the lighter neutral constituents being convected to the winter hemisphere (Johnson 1964). This anomaly is clearly seen from our results in the North America and Oceania regions. Thus, the question remains: Why is the remnant of the winter anomaly not seen in the South American nor Asian regions? One explanation is that the mean vertical winds in these two regions during nighttime are two or more times larger than those in North America and Oceania, reaching mean values of $40 \mathrm{~m} / \mathrm{s}$ during the summer. If we use the same geomagnetic latitude for the 

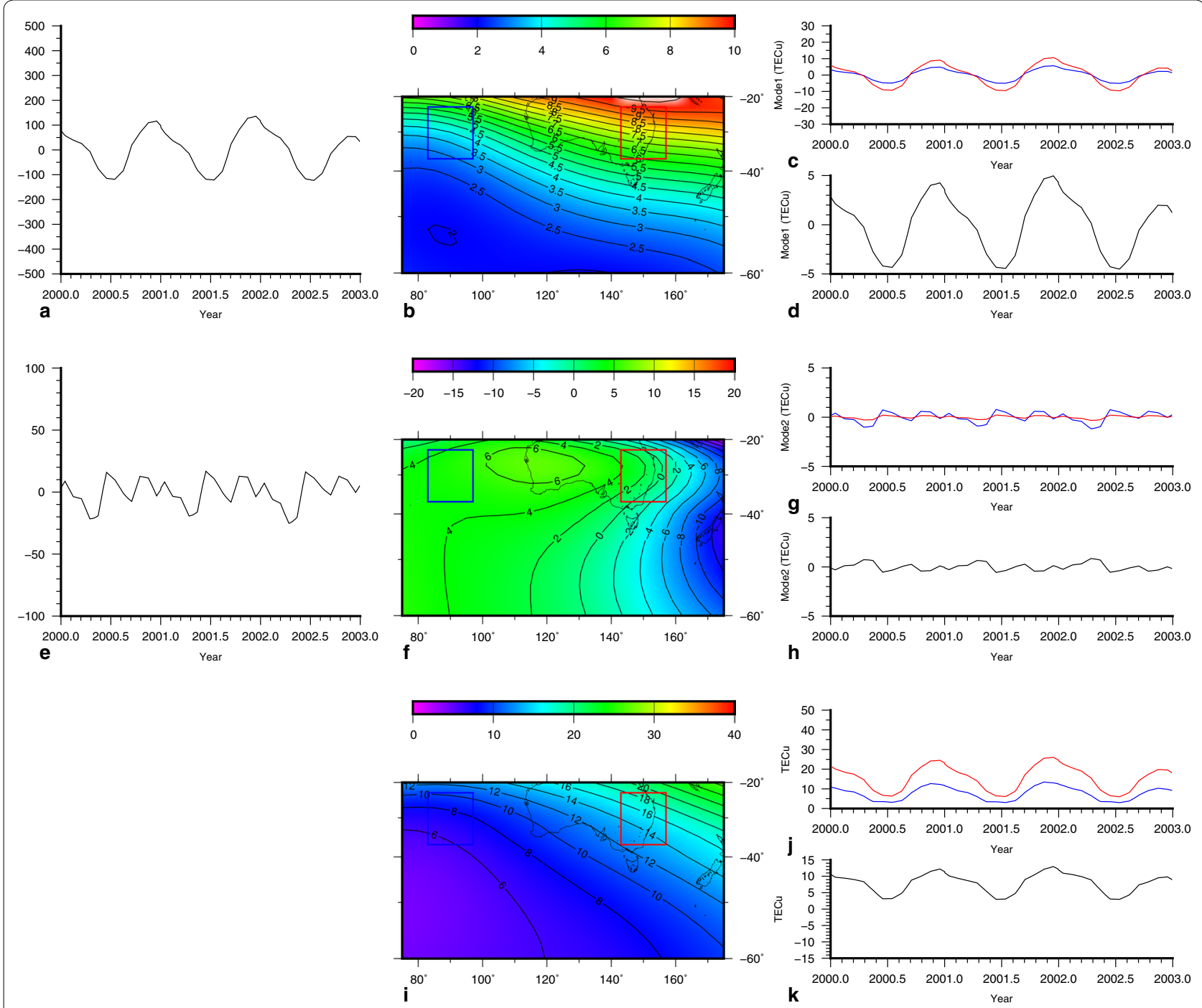

Fig. 14 Idem Fig. 13 for the Oceania region

Table 4 Mean values at 00 LT for vTEC $_{\text {GNSS }}$ and $v T E C_{I R I}$ for the four regions

\begin{tabular}{|c|c|c|c|c|}
\hline \multirow[t]{2}{*}{ Region } & \multicolumn{2}{|c|}{ vTEC $_{\text {GNSS }}(T E C u)$} & \multicolumn{2}{|c|}{$\mathrm{vTEC}_{\mathbf{I R I}}(\mathrm{TECu})$} \\
\hline & East & West & East & West \\
\hline North America & 19.7 & 15.6 & 14.9 & 10.0 \\
\hline South America & 15.7 & 20.8 & 12.8 & 20.9 \\
\hline Asia & 19.3 & 18 & 13.2 & 11.9 \\
\hline Oceania & 20.0 & 13.7 & 15.7 & 7.6 \\
\hline
\end{tabular}

four regions, i.e., $45^{\circ}$, where the MSNA and the remnant of the winter anomaly take place, then the mean vertical component of the field-aligned neutral wind $(V)$ values is 20, 41, 31, and $2 \mathrm{~m} / \mathrm{s}$ for North America, South America,
Asia, and Oceania, respectively. Although the winter anomaly, in accordance with Johnson (1964), should be observed throughout the winter hemisphere, the fact that the winds are two times larger than in Oceania and North America masks the remnant of the winter anomaly. Therefore, in South America and Asia, there are higher vTEC values at high latitudes during summer, which could be related to the MSNA. Sun et al. (2015) suggested that the MSNA is a phenomenon that moves eastward with local time in the Asian region; thus, this effect could also be happening in the Oceania region.

The longitudinal anomaly east-west difference has been reported by some authors (Zhang et al. 2011; Xu et al. 2013; Zhao et al. 2013). They have suggested that this longitudinal anomaly is caused by the difference in 
magnetic declination, which gives rise to upward and downward ion drifts across the zero declination for a given thermospheric zonal wind direction. The longitudinal anomaly is present when the east-west difference is nonzero, as shown in Figs. 3o, 4o, 5o, and 60.

The mean values of $\mathrm{vTEC}_{\mathrm{GNSS}}, \overline{\mathrm{vTEC}}_{\mathrm{GNSS}}$, and the mean values of the effective vertical component of the field-aligned neutral wind, $\bar{V}_{\text {HWM07, }}$, are computed for the east and west highlighted sectors (Table 3 ). The east-west difference of vTEC, dvTEC ${ }_{\text {GNSS, }}$ and the east-west difference of $\bar{V}_{\text {HWM07, }} \mathrm{d} \bar{V}_{\text {HWM07 }}$ show that when $\mathrm{d} \bar{V}_{\text {HWM07 }}$ is positive/negative, d $\bar{v}_{\mathrm{vEC}}$ GNSS is also positive/negative. These results agree with those of David et al. (2014). They show [Fig. 5 (bottom plot)] how the TEC is affected by the vertical ion drift acting for $2 \mathrm{~h}$. From this figure, we see that the TEC does not change when the wind speed is $80 \mathrm{~m} / \mathrm{s}$, and for lower wind values, although the TEC decreases, the relationship is not linear; i.e., the change in TEC is larger when the winds are between 0 and $10 \mathrm{~m} / \mathrm{s}$ than when they are between 10 and $20 \mathrm{~m} / \mathrm{s}$.

In our analysis (Table 3) for North America, d $\overline{\mathrm{VTEC}}_{\mathrm{GNSS}}$ is $+4 \mathrm{TECu}$, the $\mathrm{d} \bar{V}_{\mathrm{HWM} 07}$ is about $+10 \mathrm{~m} / \mathrm{s}$, and $\bar{V}_{\mathrm{HWM} 07}$ reaches values between +10 and $+20 \mathrm{~m} / \mathrm{s}$, producing a change in d $\overline{\mathrm{vTEC}}_{\mathrm{GNSS}}$ that ends up giving a value around $+4 \mathrm{TECu}$. For South America, d $\overline{\mathrm{vTEC}}_{\mathrm{GNSS}}$ is $-5 \mathrm{TECu}$ and $\mathrm{d} \bar{V}_{\mathrm{HWM} 07}$ is about $-10 \mathrm{~m} / \mathrm{s}$, but in this region the wind values are about +5 and $+15 \mathrm{~m} / \mathrm{s}$; therefore, they produce such change in the $\overline{\mathrm{vTEC}}_{\mathrm{GNSS}}$ that $\mathrm{d} \overline{\mathrm{vTEC}}_{\mathrm{GNSS}}$ ends up giving a value larger than that for North America. For Asia, $d \overline{\mathrm{vTEC}}_{\mathrm{GNSS}}$ is $+1 \mathrm{TECu}$ and there is consequently a small value of $\mathrm{d} \bar{V}_{\mathrm{HWM} 07}$. For Oceania, d $\overline{\mathrm{vTEC}}_{\mathrm{GNSS}}$ is $+6 \mathrm{TECu}$ and the $\mathrm{d} \bar{V}_{\mathrm{HWM} 07}$ is $+6 \mathrm{~m} / \mathrm{s}$; thus, in this region the values of $\bar{V}_{\text {HWM07 }}$ are lower than in the American regions, with values of 0 and $-6 \mathrm{~m} / \mathrm{s}$. Consequently, the east-west difference, d $\overline{\mathrm{VTEC}}_{\mathrm{GNSS}}$, ends up giving $+6 \mathrm{TECu}$, larger than in the American regions, although the $\mathrm{d} \bar{V}_{\mathrm{HWM} 07}$ is smaller.

To study the seasonal east-west difference of vTEC, we used the PCA-reconstructed signal (Eq. 4). Therefore, the east-west difference was computed averaging the $\operatorname{vTEC}_{\mathrm{GNSS}}^{*}(t, x)$ values inside the highlighted sectors, named $\mathrm{dvTEC}_{\mathrm{GNSS}}^{*}(t)$ (Figs. 3o, 4o, 5o, 6o; black curves). Then, to analyze its relationship with $V_{\text {HWM07, }}$, we did the same for $V_{\mathrm{HWM} 07}^{*}(t, x)$, obtaining $\overline{\mathrm{d}}_{\text {HWM07 }}^{*}(t)$ (Figs. $7 \mathrm{k}, 8 \mathrm{o}, 9 \mathrm{k}$, and $10 \mathrm{o}$, black curves). Looking at these figures, the maximum values for $\overline{\operatorname{dvTEC}}_{\mathrm{GNSS}}^{*}(t)$ are in March (with a second maximum in September) for North America, and $\overline{\mathrm{d}}_{\mathrm{HWM} 07}^{*}(t)$ shows maximum values during the equinoxes; during the December solstice for Oceania, and $\overline{\mathrm{d}}_{\mathrm{HWM} 07}^{*}(t)$ also shows a maximum value during December; in Asia the values are too small, and $\overline{\mathrm{d}}_{\mathrm{HWM} 07}^{*}(t)$ shows values near zero throughout the year; and finally in December (with a light tendency in October-November) for South America, and $\overline{\mathrm{d}}_{\mathrm{HWM} 07}^{*}(t)$ shows a maximum in September. In the last case, the $\operatorname{dvTEC}_{\mathrm{GNSS}}^{*}(t)$ and $\overline{\mathrm{d} V}_{\mathrm{HWM} 07}^{*}(t)$ seasonal variations show larger discrepancies. From the previous results (Table 3; Figs. 3o, 4o, 5o, 6o, 7k, 8o, 9k, 10o), we can conclude that the mean wind values obtained from the HWM07 model can explain quantitatively the mean east-west difference in vTEC $_{\text {GNSS }}$ behavior and are also able to closely describe, qualitatively, the seasonal variations of $\mathrm{dvTEC}_{\mathrm{GNSS}}$ for all regions except for South America. One reason for this discrepancy could be that the wind model shows some limitations in representing the horizontal winds due to the lack of measurements and physical assumptions, especially when the wind altitude is higher than $250 \mathrm{~km}$ (Drob et al. 2015). Another reason could be related to another factor that controls the higher production of vTEC at the west than at the east during night hours, which is linked to the effect of the lower atmosphere-ionosphere electrodynamical coupling and magnetosphere-ionosphere electrodynamical coupling (Xu et al. 2013). However, further study, including other wind models and/or different kinds of measurements, is needed to better understand the discrepancies in these seasonal differences.

Lastly, with respect to general features, there are some coincidences between the $\mathrm{vTEC}_{\mathrm{GNSS}}$ results and those obtained using the IRI 2012 model. These include: annual components, longitudinal anomaly, and the MSNA. It is worth noting that although IRI can reproduce these pat-


all average. On the contrary, vTEC $\mathrm{IRI}_{\mathrm{I}}$ does not show the remnant of the winter anomaly. As was mentioned previously, the change in the winter to summer ratio [O]/[N2] is one of the drivers of the winter anomaly. The IRI 2012 uses the NRLMSIS-00 model to generate this relation (Bilitza et al. 2014), and Burns et al. (2014) demonstrated that this model has some problems in reproducing the change in $[\mathrm{O}] /[\mathrm{N} 2]$. Therefore, this could be the reason why the IRI 2012 does not show this anomaly.

\section{Authors' contributions}

MPN and AM planned and led the study, interpreted the results, and drafted the manuscript. AM generated the IRI2012 and HWM07 grids. MPN processed the data. Both authors read and approved the final manuscript.

\section{Author details \\ ${ }^{1}$ Laboratorio de Meteorología espacial, Atmósfera terrestre, Geodesia, Geodinámica, diseño de Instrumental y Astrometría (MAGGIA), Facultad de Ciencias Astronómicas y Geofísicas (FCAG), Universidad Nacional de La Plata (UNLP), Paseo del Bosque s/n (1900), B1900FWA La Plata, Argentina. ${ }^{2}$ Consejo Nacional de Investigaciones Científicas y Técnicas (CONICET), Av. Rivadavia 1917, Buenos Aires, Argentina.}

\section{Acknowledgements}

This research was supported by ANPCyT Grant PICT 2012-1484 and UNLP Grant G123. The authors thank the International GNSS Service (ftp://cddis.gsfc. nasa.gov) for providing the IONEX data. Finally, we thank the two anonymous reviewers for their insightful comments on the original manuscript. 


\section{Competing interests}

The authors declare that they have no competing interests.

\section{Ethics approval and consent to participate}

Not applicable.

\section{Publisher's Note}

Springer Nature remains neutral with regard to jurisdictional claims in published maps and institutional affiliations.

\section{Appendix: Principal component analysis in one dimension}

Let $V$ contain the information of $\mathrm{vTEC}_{\mathrm{GNSS}}, \mathrm{vTEC}_{\mathrm{IRI}}$, or vertical wind obtained from HWM07. The columns are the temporal variation, and each row represents a different geographic latitude and longitude, i.e., the spatial variation:

$V=v_{i j}(t, x)=\left(\begin{array}{ccc}v_{11} & \ldots & v_{1 m} \\ \vdots & \ddots & \vdots \\ v_{n 1} & \ldots & v_{n m}\end{array}\right) \quad i=1, \ldots, n \quad j=1, \ldots, m$

First we subtract the time average on each row $\left(\overline{v_{i j}}\right)$. The new data set has zero mean.

$$
V^{\prime}=v_{i j}^{\prime}(t, x)=v_{i j}(t, x)-\bar{v}_{i j}(t, x)
$$

Second, the scatter matrix, $S$, is defined as:

$$
S=V^{\prime \mathrm{T}} V^{\prime}
$$

As $S$ is a square matrix, it has a set of orthonormal eigenvectors $\left(\mathbf{e}_{j}\right)$, enabling a representation of $S$ in a new basis. Using these $\mathbf{e}_{j}$ we can construct the principal components (or amplitudes) of the data set, $\mathbf{a}_{j}(t)$ :

$$
\boldsymbol{a}_{j}=v_{i j}^{\prime \mathrm{T}} \boldsymbol{e}_{j} \quad \text { or } \quad A=V^{\prime \mathrm{T}} E \quad\left(\text { Analysis of } V^{\prime}\right)
$$

where the columns of $E,\left\{\mathbf{e}_{1}, \mathbf{e}_{2}, \ldots, \mathbf{e}_{m}\right\}$, are the eigenvectors of $S$, and each element represents the coefficients to obtain the amplitude in each station.

These $\mathbf{a}_{j}(t)$ can be thought of as a family of time series $\left\{\mathbf{a}_{j}(t): t=1, \ldots, n\right\}$. The most important property of these time series is that they are mutually uncorrelated, carrying information about the variance of the data set along the directions $\mathbf{e}_{j}$.

Finally, and most importantly, the original centered data set can be represented exactly in the form:

$$
v_{i j}^{\prime \mathrm{T}}=a_{j} e_{j}^{\mathrm{T}} \quad \text { or } \quad V^{\prime \mathrm{T}}=A E^{\mathrm{T}} \quad\left(\text { Synthesis of } V^{\prime}\right)
$$

Received: 15 May 2017 Accepted: 10 December 2017

Published online: 20 December 2017
References

Bilitza D, Altadill D, Zhang Y, Mertens C, Truhlik V, Richards P, McKinnell L-A, Reinisch B (2014) The International Reference lonosphere 2012 —a model of international collaboration. J Space Weather Space Clim 4:A07

Burns AG, Wang W, Qian L, Solomon SC, Zhang Y, Paxton LJ, Yue X (2014) On the solar cycle variation of the winter anomaly. J Geophys Res Space Phys 119:4938-4949. https://doi.org/10.1002/2013JA019552

Chen Z, Zhang S-R, Coster AJ, Fang G (2015) EOF analysis and modeling of GPS TEC climatology over North America. J Geophys Res Space Phys 120:3118-3129. https://doi.org/10.1002/2014JA020837

David M, Sojka JJ, Schunk RW (2014) Sources of uncertainty in ionospheric modeling: the neutral wind. J Geophys Res Space Phys 119:6792-6805. https://doi.org/10.1002/2014JA020117

Drob DP, Emmert JT, Crowley G, Picone JM, Shepherd GG, Skinner W, Hays P, Niciejewski RJ, Larsen M, She CY, Meriwether JW, Hernandez G, Jarvis MJ, Sipler DP, Tepley CA, O'Brien MS, Bowman JR, Wu Q, Murayama Y, Kawamura S, Reid IM, Vincent RA (2008) An empirical model of the Earth's horizontal wind fields: HWM07. J Geophys Res 113:A12304. https://doi. org/10.1029/2008ja013668

Drob DP, Emmert JT, Meriwether JW, Makela JJ, Doornbos E, Conde M, Hernández G, Noto J, Zawdie K, McDonald SE, Huba JD, Klenzing JH (2015) An update to the Horizontal Wind Model (HWM): the quiet time thermosphere. Earth Space Sci 2:301-319. https://doi. org/10.1002/2014EA000089

Hagan ME (1993) Quiet time upper thermospheric winds over millstone hill between 1984 and 1990. J Geophys Res 98:3731-3739

Hernández-Pajares M, Juan J, Sanz J, Orus R, Garcia-Rigo A, Feltens J, Komjathy A, Schaer S, Krankowski A (2009) The IGS VTEC maps: a reliable source of ionospheric information since 1998. J Geod 83(3-4):263-275

Horvath I (2006) A total electron content space weather study of the nighttime Weddell Sea Anomaly of 1996/1997 southern summer with TOPEX/Poseidon radar altimetry. J Geophys Res 111:A12317. https://doi. org/10.1029/2006JA011679

Horvath I, Essex EA (2003) The Weddell Sea Anomaly observed with the TOPEX satellite data. J Atmos Sol Terr Phys 65:693-706. https://doi.org/10.1016/ S1364-6826(03)00083-X

Hsu ML, Lin CH, Hsu RR, Liu JY, Paxton LJ, Su HT, Tsai HF, Rajesh PK, Chen CH (2011) The O I $135.6 \mathrm{~nm}$ airglow observations of the midlatitude summer nighttime anomaly by TIMED/GUVI. J Geophys Res 116:A07313. https:// doi.org/10.1029/2010JA016150

Huang Z, Du W, Chen B (2005) Deriving private information from randomized data. Electrical engineering and computer science. Paper 10. http://surface.syr.edu/eecs/10

Jee G, Schunk RW, Scherliess L (2004) Analysis of TEC data from the TOPEX/Poseidon mission. J Geophys Res 109:A01301. https://doi. org/10.1029/2003JA010058

Jee G, Burns AG, Kim Y-H, Wang W (2009) Seasonal and solar activity variations of the Weddell Sea Anomaly observed in the TOPEX total electron content measurements. J Geophys Res 114:A04307. https://doi. org/10.1029/2008JA013801

Johnson FS (1964) Composition changes in the upper atmosphere. In: Thrane $\mathrm{E}$ (ed) Electron density distribution in ionosphere and exosphere. NorthHolland Publ., Amsterdam, pp 81-84

Lin CH, Liu JY, Cheng CZ, Chen CH, Liu CH, Wang W, Burns AG, Lei J (2009) Three-dimensional ionospheric electron density structure of the Weddell Sea Anomaly. J Geophys Res 114:A02312. https://doi. org/10.1029/2008JA013455

Lin CH, Liu CH, Liu JY, Chen CH, Burns AG, Wang W (2010) Midlatitude summer nighttime anomaly of the ionospheric electron density observed by FORMOSAT-3/COSMIC. J Geophys Res 115:A03308. https://doi. org/10.1029/2009JA014084

Liu H, Thampi SV, Yamamoto M (2010) Phase reversal of the diurnal cycle in the midlatitude ionosphere. J Geophys Res 115:A01305. https://doi. org/10.1029/2009JA014689

Mannucci A, Wilson B, Yuan D, Ho C, Lindqwister U, Runge T (1998) A global technique for GPS-derived ionospheric total electron content measurements. Radio Sci 33:565-582 
Meza A, Natali MP, Fernández LI (2015) PCA analysis of the nighttime anomaly in far-from-geomagnetic pole regions from VTEC GNSS data. Earth Planets Space 67(1):1-14. https://doi.org/10.1186/s40623-015-0281-4

Mikhailov AV, Förster M, Leschinskaya TY (2000) On the mechanism of the post-midnight winter NmF2 enhancements: dependence on solar activity. Ann Geophys 18:1422-1434

Preisendorfer RW (1988) Principal component analysis in meteorology and oceanography. Elsevier, Amsterdam

Richards PG, Chang T, Comfort RH (2000) On the causes of the annual variation in the plasmaspheric electron density. J Atmos Sol Terr Phys 62:935-946. https://doi.org/10.1016/\$1364-6826(00)00039-0

Rishbeth H (1998) How the thermospheric circulation affects the ionospheric F2-layer. J Atmos Sol Terr Phys 60:1385-1402

Rishbeth H, Garriot OK (1969) Introduction to ionospheric physics. Academic Press, New York

Sun Y-Y, Matsuo T, Maruyama N, Liu J-Y (2015) Field-aligned neutral wind bias correction scheme for global ionospheric modeling at midlatitudes by assimilating FORMOSAT-3/COSMIC $h_{m} F_{2}$ data under geomagnetically conditions. J Geophys Res Space Phys. https://doi. org/10.1002/2014ja020768
Thampi SV, Lin CH, Liu H, Yamamoto M (2009) First tomographic observations of the mid-latitude summer nighttime anomaly (MSNA) over Japan. J Geophys Res 114:A10318. https://doi.org/10.1029/2009JA014439

Titheridge JE (1995) Winds in the ionosphere-a review. J Atmos Terr Phys 57(14):1681-1714

Wackernagel H (1998) Multivariate geostatistics: an introduction with applications, 2nd edn. Springer, Berlin

Xu JS, Li XJ, Liu YW, Jing M (2013) TEC differences for the mid-latitude ionosphere in both sides of the longitudes with zero declination. Adv Space Res. https://doi.org/10.1016/j.asr.2013.01.010

Zhang S, Foster JC, Coster AJ, Erickson PJ (2011) East-West Coast differences in total electron content over the continental US. Geophys Res Lett 38:L19101. https://doi.org/10.1029/2011gl049116

Zhang Y, Paxton LJ, Kil H (2013) Nightside midlatitude ionospheric arcs: TIMED/ GUVI observations. J Geophys Res (Space Phys) 118:3584-3591. https:// doi.org/10.1002/jgra.50327

Zhao B, Wang M, Wang Y, Ren Z, Yue X, Zhu J, Wan W, Ning B, Liu J, Xiong B (2013) East-west differences in F-region electron density at midlatitude: evidence from the Far East region. J Geophys Res Space 118:542-553. https://doi.org/10.1029/2012ja018235

\section{Submit your manuscript to a SpringerOpen ${ }^{\circ}$ journal and benefit from:}

- Convenient online submission

- Rigorous peer review

- Open access: articles freely available online

- High visibility within the field

- Retaining the copyright to your article

Submit your next manuscript at springeropen.com 